\title{
A DECENTRALIZED APPROACH TO GENERAL EQUILIBRIUM ANALYSIS
}

Emanuel R. Leão

Julho 2008

WP $\mathrm{n}=2008 / 66$

DOCUMENTO DE TRABALHO

WORKI NG PAPER 
Abstract

1. INTRODUCTION

2. THE MODEL

4. THE TYPICAL HOUSEHOLD'S BEHAVIOUR

5. THE MARKET CLEARING CONDITIONS

6.THE COMPETITIVE EQUILIBRIUM

7. THE COMPETITIVE EQUILIBRIUM ASSUMING RATIONAL EXPECTATIONS

ANNEXES

\footnotetext{
${ }^{1}$ Departament of Economics, Instituto Superior de Ciências do Trabalho e da Empresa and Dinâmia Centro de Estudos sobre a Mudança Socioeconómica, Avenida das Forças Armadas, 1649-026 Lisboa, Portugal, Phone: 00351217903236, Fax: 00351217903933 - E-mail: emanuel.leao@iscte.pt
} 


\section{Introduction}

In this paper we develop a decentralized zero growth version of the model in King, Plosser and Rebelo (1988). By zero growth model we mean a model where physical output is constant in the steady-state. Note that, for the purposes of simulation, King, Plosser and Rebelo also transform their exogenous growth model into a model which is essentially a zero growth model.

Our use of a decentralized version can also be explained. First, with a decentralized approach the assumptions we are using and their role become clearer. For example, with a Constant Returns to Scale production function the number of households and the number of firms is not important in terms of describing the equilibrium behaviour of the economy. But we may want to try other technologies.

Second, the decentralized approach is more general. It can be used even when the assumptions of the second welfare theorem do not hold. Imperfect competition and distorting taxation are examples of realities which cannot be tackled using the second welfare theorem.

In the model we construct, there are only two types of economic agents: households and firms. It is also important to note from the outset that we only have real variables in the model.

\section{The model}

This is a closed economy model with no government. There are $\mathrm{H}$ homogeneous households and $\mathrm{F}$ homogeneous firms operating in this economy. There is only one (homogeneous) physical good produced in this economy which we denote physical output. There are two possible uses for this output: it can be consumed or it can be used for investment (i.e. used to increase the capital stock).

We next examine the typical household's preferences, the technology available in the economy (production function and capital accumulation equation), the resource constraints that exist in a given period and the market structure.

Let us suppose that we are at $t_{0}$ and that households and firms are considering decisions for periods $\left(t_{0}+j\right)$ with $j=0,1,2,3, \ldots$ 
Let us start by describing the preferences of the typical household.

Utility in period $\left(t_{0}+j\right)$ is given by

$$
u\left(c_{t_{0}+j}, \ell_{t_{0}+j}\right)
$$

where $c_{t_{0}+j}$ is the flow of consumption during period $\left(t_{0}+j\right)$ and $\ell_{t_{0}+j}$ is the amount of leisure enjoyed in that period. The function $u(.,$.$) is assumed to be twice continuously differentiable and$ strictly concave with $u_{1}(c, \ell)>0, u_{2}(c, \ell)>0, u_{11}(c, \ell)<0$ and $u_{22}(c, \ell)<0$. Here, $u_{i}$ denotes the first partial derivative of $u(.,$.$) with respect to its ith variable and u_{i i}$ is the partial derivative of $u_{i}$ with respect to the ith variable. The function $u(.,$.$) is also assumed to fulfill the Inada conditions$ $\lim _{c \rightarrow 0} u_{1}(c, \ell)=+\infty, \lim _{\ell \rightarrow 0} u_{2}(c, \ell)=+\infty, \lim _{c \rightarrow+\infty} u_{1}(c, \ell)=0$ and $\lim _{\ell \rightarrow+\infty} u_{2}(c, \ell)=0$.

The household maximizes the discounted sum of its stream of utilities from $t_{0}$ till the end of time $^{1}$, i.e., it maximizes

$$
U_{t_{0}}=E_{t_{0}}\left[\sum_{j=0}^{j=\infty} \beta^{j} u\left(c_{t_{0}+j}, \ell_{t_{0}+j}\right)\right]
$$

where $\beta$ is a discount factor $(0<\beta<1)$ that reflects a preference for current over future consumption-leisure bundles ${ }^{2}$. Application of the operator $E_{t_{0}}[$.$] yields the mathematical expec-$ tation, conditional on complete information pertaining to period $t_{0}$ and earlier, of the indicated argument.

Let us now describe the technology available in the economy: production function and capital accumulation equation. There is a single final good in this economy which, as already mentioned, we denote physical output. Each firm's production function is described by

$$
y_{t_{0}+j}=A_{t_{0}+j} F\left(k_{t_{0}+j}, n_{t_{0}+j}^{d}\right)
$$

where $y_{t_{0}+j}$ is the physical output of the firm in period $\left(t_{0}+j\right), A_{t_{0}+j}$ is a technological parameter, $k_{t_{0}+j}$ is the firm's capital stock and $n_{t_{0}+j}^{d}$ is the firm's labour demand in period $\left(t_{0}+j\right)$.

\footnotetext{
${ }^{1}$ We assume that households are infinitely-lived. The assumption of infinitely-lived households can be interpreted as households with finite lifetime plus an operational bequest motive linking the utility of the current generation with the utility of future generations.

${ }^{2}$ It is obvious that, since $0<\beta<1$, the weight of utilities in periods that are far from the present counts little when compared with the weight of utilities in periods nearer to the present.
} 
The function $A F(.,$.$) is a Constant Returns to Scale production function. It is twice continu-$ ously differentiable and concave with positive but decreasing marginal productivity of capital and positive but decreasing marginal productivity of labour. It satisfies the following Inada conditions: $\lim _{k \rightarrow 0} A F_{1}\left(k, n^{d}\right)=+\infty, \lim _{n^{d} \rightarrow 0} A F_{2}\left(k, n^{d}\right)=+\infty, \lim _{k \rightarrow+\infty} A F_{1}\left(k, n^{d}\right)=0$ and $\lim _{n^{d} \rightarrow+\infty} A F_{2}\left(k, n^{d}\right)=0$. Both factors of production are assumed to be essential in production which means that $A F\left(0, n^{d}\right)=$ 0 and $A F(k, 0)=0$.

$A_{t_{0}+j}$ is the realization in period $\left(t_{0}+j\right)$ of a random variable that represents the state of the technology. Changes in $A_{t_{0}+j}$ are changes in "total factor productivity". We assume that the realization of $A_{t_{0}+j}$ is known at the beginning of period $\left(t_{0}+j\right)$.

Physical output can either be consumed by households or stored by firms. Stored output increases next period's capital stock, i.e., it represents investment ${ }^{3}$.

Capital accumulation is described by

$$
k_{t_{0}+1+j}=(1-\delta) k_{t_{0}+j}+i_{t_{0}+j}
$$

where $i_{t_{0}+j}$ is the flow of investment in period $\left(t_{0}+j\right)$ and $\delta$ is the per-period rate of physical depreciation of the stock of capital. $\delta$ is assumed to be constant and belonging to the closed interval $[0,1]$.

The resource constraints are as follows. Each firm starts period $\left(t_{0}+j\right)$ with a stock of capital $k_{t_{0}+j}$ which is pre-determined [ which was determined in $\left(t_{0}-1+j\right)$ ]. In other words, the stock of capital that will enter the production function in $\left(t_{0}+j\right)$ cannot be changed by decisions taken during $\left(t_{0}+j\right)$. Each household has an endowment of time per-period which is normalized to one by an appropriate choice of units. This amount of time can either be used to work or to rest. Therefore, we can write

$$
n_{t_{0}+j}^{s}+\ell_{t_{0}+j} \leq 1
$$

where $n_{t_{0}+j}^{s}$ is the household's supply of labour during $\left(t_{0}+j\right)$.

\footnotetext{
${ }^{3}$ Note that this implies that the price of consumption goods and the price of investment goods is the same. To deviate from this assumption would require a two-sector model where the final good would be produced in one industry and physical capital would be produced in the other industry.
} 
The previous assumptions about preferences and technology ensure that, at an optimal solution, we will have

$$
n_{t_{0}+j}^{s}+\ell_{t_{0}+j}=1
$$

This is because any tiny amount of time can be used to increase the level of utility either by raising the amount of leisure (we are assuming non-satiety in leisure except at infinity) or by using it to work and use the increased wage earnings to raise the level of consumption.

Finally, we describe the market structure. There are four markets: the goods market, the labour market, the loans market and the shares market. $H$ and $F$ are assumed to be large enough to guarantee that all agents are price-takers. Prices are perfectly flexible and adjust so as to clear all markets in every period. There are three prices in this model: the real wage, the real interest rate and the price of shares in real terms. All these prices are measured in units of output. We can think of these three prices as adjusting to clear the labour market, the loans market and the shares market, respectively. If these three markets are in equilibrium, then (by Walras Law), the goods market is also in equilibrium.

\section{The typical firm's behaviour}

Each firm uses capital and labour to produce physical output. The profits earned by each firm in a given period are distributed to households in the form of dividends.

Each firm $\mathrm{f}(f=1,2, \ldots, F)$ maximizes the Value of its Assets (VA), i.e., the expected discounted value of the stream of present and future dividends. Therefore, when we are at $t_{0}$, the typical firm's optimization problem is

$$
\underset{n_{t_{0}+j}^{d}, k_{t_{0}+1+j}}{\operatorname{Max}} V A=E_{t_{0}}\left[\sum_{j=0}^{j=\infty} \frac{1}{1+r_{t_{0}, t_{0}+j}} \pi_{t_{0}+j}^{f}\right]
$$

where

$$
\begin{gathered}
\pi_{t_{0}+j}^{f}=A_{t_{0}+j} F\left(k_{t_{0}+j}, n_{t_{0}+j}^{d}\right)-w_{t_{0}+j} n_{t_{0}+j}^{d}-\left[k_{t_{0}+1+j}-(1-\delta) k_{t_{0}+j}\right] \\
\text { for } \mathrm{j}=0,1,2, \ldots
\end{gathered}
$$


where $w_{t_{0}+j}$ is the real wage in period $\left(t_{0}+j\right)$.

The only loans market in this model is the one-period loans market (there are no markets for loans of other maturities). Therefore, $\left(1+r_{t_{0}, t_{0}+j}\right)$ [meant to represent the real interest rate between $t_{0}$ and $\left.\left(t_{0}+j\right)\right]$ must be

$$
\begin{aligned}
& \left(1+r_{t_{0}, t_{0}+j}\right)=1 \quad \text { for } \mathrm{j}=0 \\
& \left(1+r_{t_{0}, t_{0}+j}\right)=\left(1+r_{t_{0}}\right)\left(1+r_{t_{0}+1}\right)\left(1+r_{t_{0}+2}\right) \ldots\left(1+r_{t_{0}+j-1}\right) \text { for } \mathrm{j}=1,2,3, \ldots
\end{aligned}
$$

where $r_{t}$ is the real interest rate between period $t$ and period $(t+1)$.

There is also an initial condition for the capital stock. We denote the typical firm's initial capital stock by $k_{t_{0}}$. We assume $k_{t_{0}}>0$.

There is also a transversality condition on the capital stock. This condition is given by

$$
\lim _{j \rightarrow+\infty} E_{t_{0}}\left[\beta^{j} u_{1}\left(c_{t_{0}+j}, n_{t_{0}+j}^{s}\right) k_{t_{0}+1+j}\right]=0
$$

Let us summarize the meaning of this condition. In period $\left(t_{0}+j\right)$, the firm chooses $k_{t_{0}+1+j}$. As $j \rightarrow+\infty,\left(t_{0}+j\right) \rightarrow+\infty$. In other words, making $j \rightarrow+\infty$ corresponds to making $\left(t_{0}+j\right)$ tend to the end of the world. Hence, $\left(t_{0}+1+j\right)$ denotes the period after the end of the world and $k_{t_{0}+1+j}$ the capital stock that is left for the period after the world has ended. Since $u_{1}\left(c_{t_{0}+j}, n_{t_{0}+j}^{s}\right)$ denotes the marginal utility of consumption in period $\left(t_{0}+j\right), \beta^{j} u_{1}\left(c_{t_{0}+j}, n_{t_{0}+j}^{s}\right) k_{t_{0}+1+j}$ denotes the present utility value of the capital stock that the firm leaves for the period that follows the end of the world ( remember that, in this model, units of capital correspond to units of output). Therefore, $\lim _{j \rightarrow+\infty} E_{t_{0}}\left[\beta^{j} u_{1}\left(c_{t_{0}+j}, n_{t_{0}+j}^{s}\right) k_{t_{0}+1+j}\right]$ represents the way a shareholder in $t_{0}$ views the utility value of the capital stock that the firm is planning to leave for the period that follows the end of the world. Hence, the transversality condition given by 1 is merely saying that the utility value of the capital stock that the firm is planning to leave for the period that follows the end of the world (as evaluated by a shareholder in $t_{0}$ ) must be zero. In other words, this transversality condition says that, if the world is going to end in a certain period, the firm must either not leave capital for the period that follows the end of the world (giving it for shareholders to use on the period the world ends or before would be a better solution) or if the firm is planning to leave a positive capital stock for the period that follows the end of the world, it must be because the marginal utility that the shareholders would obtain from receiving it at the world's last period 
would be zero ${ }^{4}$.

The transversality condition plays the important role of eliminating the possibility that the firm would forever accumulate capital at an excessive rate, something which none of the first-order conditions prevents.

Also, we have non-negativity constraints: $n_{t_{0}+j}^{d} \geq 0$ and $k_{t_{0}+1+j} \geq 0$ for $\mathrm{j}=0,1,2, \ldots$.

The assumptions about technology that we made imply that we could never have an optimal solution with $n_{t_{0}+j}^{d}=0$ for any $\mathrm{j}$. Since $n^{d}$ is essential in production, $n_{t_{0}+j}^{d}=0$ would imply zero physical output in period $\left(t_{0}+j\right)$. On the other hand, the Inada condition $\lim _{n^{d} \rightarrow 0} A F_{2}\left(k, n^{d}\right)=+\infty$ tells us that, if $n_{t_{0}+j}^{d}=0$, then the firm would obtain an enormous amount of output simply by raising $n_{t_{0}+j}^{d}$ by a tiny amount. This would lead the firm to indeed increase $n_{t_{0}+j}^{d}$. Therefore, $n_{t_{0}+j}^{d}=0$ could never be an optimal solution.

A similar reasoning leads us to conclude that we could never have an optimal solution with $k_{t_{0}+1+j}=0$ for any $\mathrm{j}$

We can summarize as follows. There is a non-negativity constraint for each of the two variables but we have assumptions which guarantee that none of the variables will be equal to zero at an optimal solution. Therefore, the optimal solution is not a corner solution. Thus, standard first-order conditions (equalities) are necessary conditions for the optimal solution.

The first-order conditions to the firm's optimization problem are:

$$
\begin{gathered}
\frac{\partial V A}{\partial n_{t_{0}+j}^{d}}=E_{t_{0}}\left[\frac{A_{t_{o}+j} F_{2}\left(k_{t_{0}+j}, n_{t_{0}+j}^{d}\right)-w_{t_{0}+j}}{\left(1+r_{t_{0}}\right) \ldots\left(1+r_{t_{0}-1+j}\right)}\right]=0 \\
\frac{\partial V A}{\partial k_{t_{0}+1+j}}=E_{t_{0}}\left[\frac{(-1)}{\left(1+r_{t_{0}}\right) \ldots\left(1+r_{t_{0}-1+j}\right)}\right] \\
+E_{t_{0}}\left[\frac{A_{t_{o}+1+j} F_{1}\left(k_{t_{0}+1+j}, n_{t_{0}+1+j}^{d}\right)+(1-\delta)}{\left(1+r_{t_{0}}\right) \ldots\left(1+r_{t_{0}-1+j}\right)\left(1+r_{t_{0}+j}\right)}\right]=0
\end{gathered}
$$

$$
\text { for } j=0,1,2,3, \ldots
$$

We have already explained that equations 2 and 3 are necessary for an optimal solution.

\footnotetext{
${ }^{4}$ Note that the shareholders in this model are the households.
} 
Since the function $A F(.,$.$) is concave, the weights \frac{1}{1+r_{t_{0}, t_{0}+j}}$ are positive, and $E_{t_{0}}[$.$] is a linear$ operator which will be applied to a reality whose events occur with positive probability, we can conclude that the objective function is also concave. Therefore, equations 2 and 3 are also sufficient for a maximum.

In the appendix, we derive the first order conditions of the firm's problem in an intuitive way and it is easy to see that the conditions derived using mathematics correspond to the ones we obtain in an intuitive way.

Since it is not possible, in general, to obtain an explicit solution to the firm's optimization problem, we take equations 2 and 3 as representing this solution (because these equations represent the solution in an implicit way). The optimal solution includes, among other values, values for period $t_{0}: n_{t_{0}}^{d}$ and $k_{t_{0}+1}$. Given the (pre-determined) value of $k_{t_{0}}$ this implies a value for $y_{t_{0}}=$ $A_{t_{0}} F\left(k_{t_{0}}, n_{t_{0}}^{d}\right)$ and a value for $i_{t_{0}}=k_{t_{0}+1}-(1-\delta) k_{t_{0}}$.

We can conclude that equations 2 and 3 give, in an implicit way, the firm's demand and supply functions for period $t_{0}\left(n_{t_{0}}^{d}, i_{t_{0}}\right.$ and $\left.y_{t_{0}}\right)$ as well as planned demand and supply functions for all future periods. The firm's demand and supply functions for period $t_{0}$ will depend on the current values of the various prices (real wage, real interest rate), on the firm's initial capital stock, on the value of the technological parameter in period $t_{0}$ and on the expectations of the firm about the future.

\section{The typical household's behaviour}

At $t_{0}$ the household is facing the following sequence of budget constraints

$$
\begin{gathered}
w_{t_{0}+j} n_{t_{0}+j}^{s}+\sum_{f=1}^{f=F} z_{t_{0}+j}^{f} \pi_{t_{0}+j}^{f}+\sum_{f=1}^{f=F} z_{t_{0}+j}^{f} q_{t_{0}+j}^{f}+\frac{b_{t_{0}+1+j}}{1+r_{t_{0}+j}} \geq c_{t_{0}+j}+b_{t_{0}+j}+\sum_{f=1}^{f=F} z_{t_{0}+1+j}^{f} q_{t_{0}+j}^{f} \\
\text { for } \mathrm{j}=0,1,2,3, \ldots
\end{gathered}
$$

All terms are measured in units of output (in real terms). Let us examine these budget constraints in detail. The way loans work in this model is as follows. In a given period (period t, for example), the household can either borrow from other households $\left(b_{t+1}>0\right)$ or lend to other households $\left(b_{t+1}<0\right)$. If it borrows $\frac{1}{1+r_{t}}$ units of output in period $t\left[r_{t}\right.$ is the interest rate 
between period $\mathrm{t}$ and period $(\mathrm{t}+1)$ measured in units of output, i.e., the real interest rate between period $\mathrm{t}$ and period $(\mathrm{t}+1)]$, it shall have to pay $\frac{1}{1+r_{t}}\left(1+r_{t}\right)=1$ units of output in period $(\mathrm{t}+1)$. Therefore, if the household borrows $b_{t+1} \frac{1}{1+r_{t}}$ units of output in period $t$, it will have to pay $b_{t+1} \frac{1}{1+r_{t}}\left(1+r_{t}\right)=b_{t+1}$ units of output in period $(\mathrm{t}+1)$.

The way shares work in this model is as follows. $q_{t}^{f}$ is the price [measured in units of output] that the household would have to pay to buy $100 \%$ of firm $\mathrm{f}$ in period t. $z_{t}^{f}$ is the percentage of firm $\mathrm{f}$ [i.e. the share of firm $\mathrm{f}$ ] that the household bought in period (t-1) and sells in period t. $z_{t}^{f}$ entitles the household to a share in the dividends of firm $\mathrm{f}$ generated in period $t$, i.e., it entitles the household to receive the amount $z_{t}^{f} \pi_{t}^{f}$ during period t. After receiving these dividends, households can trade shares ${ }^{5}$. In period $\mathrm{t}$, the household sells the amount $z_{t}^{f}$ and buys the amount $z_{t+1}^{f}$ (hence, $z_{t+1}^{f}$ is the percentage of firm $\mathrm{f}$ that the household buys in period $\mathrm{t}$ ). $z_{t+1}^{f}$ entitles the household to a share in the dividends of firm $f$ generated in period $(t+1)$, i.e., it entitles the household to receive the amount $z_{t+1}^{f} \pi_{t+1}^{f}$ during period $(t+1)$. The percentages $z_{t}^{f}$ and $z_{t+1}^{f}$ are measured as a number belonging to the closed interval $[0,1]$. So, $\left(z_{t+1}^{f}-z_{t}^{f}\right)$ is the net percentage of firm $\mathrm{f}$ that the household buys in period t. Therefore, $q_{t}^{f}\left(z_{t+1}^{f}-z_{t}^{f}\right)$ is the amount that the household spends on shares of firm $\mathrm{f}$ in period t. To make this clear, suppose that $z_{t}^{f}=0$ and that the household wants to buy the whole of firm $\mathrm{f}$ in period t so that $z_{t+1}^{f}=1$; then clearly it would have to pay $q_{t}^{f}$ $(1-0)=q_{t}^{f}$ units of output which fits our definition of $q_{t}^{f}$.

The interpretation of the budget constraint is as follows. In the left-hand side of the constraint, $w_{t_{0}+j} n_{t_{0}+j}^{s}$ is the amount that the household receives as wages during period $\left(t_{0}+j\right)$. The term $\sum_{f=1}^{f=F} z_{t_{0}+j}^{f} \pi_{t_{0}+j}^{f}$ denotes the amount of dividends that the household receives in period $\left(t_{0}+j\right)$ in return for the shares of the F firms that it bought in period $\left(t_{0}-1+j\right)$. The term $\sum_{f=1}^{f=F} z_{t_{0}+j}^{f} q_{t_{0}+j}^{f}$ denotes the amount the household receives in period $\left(t_{0}+j\right)$ from selling the shares of the $\mathrm{F}$ firms that it bought in period $\left(t_{0}-1+j\right)$. The term $\frac{b_{t_{0}+1+j}}{1+r_{t_{0}+i}}$ is the amount that the household borrows from other households in period $\left(t_{0}+j\right)$. All these terms are measured in units of output.

In the right-hand side of the constraint, $c_{t_{0}+j}$ is consumption expenditure in period $\left(t_{0}+j\right)$, $b_{t_{0}+j}$ is the amount that the household has to pay to other households in period $\left(t_{0}+j\right)$ because of the credit it obtained in the previous period [in period $\left(t_{0}-1+j\right)$ ], and $\sum_{f=1}^{f=F} z_{t_{0}+1+j}^{f} q_{t_{0}+j}^{f}$ is

\footnotetext{
${ }^{5}$ In equilibrium, they won't trade shares with each other because they are all equal to each other.
} 
the household's expenditure buying shares of the F firms in period $\left(t_{0}+j\right)$. All these terms are measured in units of output. Note that in period $t_{0}$ the household sells all the shares of the F firms it had bought in period $\left(t_{0}+1\right)$ and then she buys new amounts of shares.

The previous assumptions about preferences ensure that, at an optimal solution, this budget constraint will hold as an equality. This is because any unit of output can be used to increase the level of utility. For example, consuming it in period $\left(t_{0}+j\right)$ will increase utility because we are assuming non-satiety in consumption except at infinity.

Consequently, at $t_{0}$ the household is looking into the future and maximizes the present discounted value of lifetime utility subject to the relevant constraints as follows:

$$
\begin{aligned}
& \underset{c_{t_{0}+j}, \ell_{t_{0}+j}, n_{t_{0}+j}^{s}, b_{t_{0}+1+j}, z_{t_{0}+1+j}^{f}}{\operatorname{Max}} E_{t_{0}}\left[\sum_{j=0}^{j=\infty} \beta^{j} u\left(c_{t_{0}+j}, \ell_{t_{0}+j}\right)\right] \\
& \text { s.t. } \\
& w_{t_{0}+j} n_{t_{0}+j}^{s}+\sum_{f=1}^{f=F} z_{t_{0}+j}^{f} \pi_{t_{0}+j}^{f}+\sum_{f=1}^{f=F} z_{t_{0}+j}^{f} q_{t_{0}+j}^{f}+\frac{b_{t_{0}+1+j}}{1+r_{t_{0}+j}}=c_{t_{0}+j}+b_{t_{0}+j}+\sum_{f=1}^{f=F} z_{t_{0}+1+j}^{f} q_{t_{0}+j}^{f} \\
& n_{t_{0}+j}^{s}+\ell_{t_{0}+j}=1 \\
& \text { for } \mathbf{j}=0,1,2,3, \ldots
\end{aligned}
$$

We also have initial conditions and a transversality condition. There are initial conditions on holdings of shares. Assuming that we had market clearing ${ }^{6}$ in the shares' market in period $\left(t_{0}-1\right)$, these initial conditions for period $t_{0}$ will be $z_{t_{0}}^{f}=\frac{1}{H}$ and $s_{t_{0}}^{l}=\frac{1}{H}$. There is an initial condition defining the household's initial debt position. Assuming that we had market clearing in the loans market in period $\left(t_{0}-1\right)$, this initial condition for period $t_{0}$ will be $b_{t_{0}}=0$. There is also a standard transversality condition on the amount of borrowing by the household which is given by

$$
\lim _{j \rightarrow+\infty} E_{t_{0}}\left[\frac{1}{\left(1+r_{t_{0}}\right)\left(1+r_{t_{0}+1}\right)\left(1+r_{t_{0}+2}\right) \ldots\left(1+r_{t_{0}+j-1}\right)} b_{t_{0}+1+j}\right]=0
$$

This transversality condition is theoretically relevant. It means that the pattern of borrowing by an household must be such that at the end of the world, the household owes nothing (put

\footnotetext{
${ }^{6}$ Market clearing conditions will be derived in the next section.
} 
more precisely, it either owes nothing or, if it owes something, the amount it owes is so small that, as evaluated from today, it is worth nothing). This prevents one household from consuming at the expense of others during its lifetime. In the model we have at hand, this condition won't be important in terms of describing the competitive equilibrium because market clearing conditions in the loans market and Rational Expectations will ensure that it holds.

Finally, there are also non-negativity constraints: $c_{t_{0}+j} \geq 0, \ell_{t_{0}+j} \geq 0, n_{t_{0}+j}^{s} \geq 0$ and $z_{t_{0}+1+j}^{p} \geq 0$ for $\mathrm{j}=0,1,2, \ldots$

The assumptions about preferences that we made imply that we could never have an optimal solution with $c_{t_{0}+j}=0$ for any $\mathrm{j}$. The proof of this is as follows. $u_{11}(c, \ell)<0$ tells us that, as $c_{t}$ decreases, $u_{1}(c, \ell)$ increases. The respective Inada condition $\left[\lim _{c \rightarrow 0} u_{1}(c, \ell)=+\infty\right]$ tells us that this happens in such a way that, as $c_{t_{0}+j} \rightarrow 0$, the increase in utility that would result from consuming one extra unit becomes very large (it approaches infinity). Hence, if $c_{t_{0}+j}$ was equal to zero the household would always be compelled to obtain a tiny bit of consumption good (for example, working a little bit and using the income earned from it to buy a small amount of the consumption good).

A similar reasoning leads us to conclude that we could never have an optimal solution with $\ell_{t_{0}+j}=0$ for any $\mathrm{j}$.

A solution with $n_{t_{0}+j}^{s}=0$ for one or more $\mathrm{j}_{\mathrm{s}}$ is theoretically possible. The household could, for example, use share income to consume. However, in this chapter we are interested in the competitive general market equilibrium with homogeneous households. At such an equilibrium, $n_{t_{0}}^{s}=0$ will not occur because the market equilibrium condition in the labour market implies that all households work an equal (positive) number of hours ${ }^{7}$. With Rational Expectations, the household takes into account future market clearing conditions in making its plans and, as a consequence, it will not plan $n_{t_{0}+j}^{s}=0$. Since the equilibrium we are interested in is the competitive general market equilibrium of an economy with homogeneous agents under Rational Expectations, the solution to the household's problem that we are looking for is one where $n_{t_{0}+j}^{s}>0$.

A solution with $z_{t_{0}+1+j}^{f}=0$ for one or more $\mathrm{j}_{\mathrm{s}}$ is theoretically possible. An household could simply choose to work and use the wage income to consume without engaging in the purchase of

\footnotetext{
${ }^{7}$ Market clearing conditions will be derived in the next section.
} 
shares. However, in this chapter, we are interested in the competitive general market equilibrium with homogeneous households. At such an equilibrium, $z_{t_{0}+1}^{f}=0$ will not occur because the market equilibrium condition in the shares' market will make every household hold an equal (positive) share of each firm. With Rational Expectations, the household takes into account future market clearing conditions in making its plans and, as a consequence, it will not plan $z_{t_{0}+1+j}^{f}=0$. Since the equilibrium we are interested in is the competitive general market equilibrium of an economy with homogeneous agents under Rational Expectations, the solution to the household's problem that we are looking for is one where $z_{t_{0}+1+j}^{f}>0$.

Since for all variables that have a non-negativity constraint we can conclude that the value of the variable at the optimal solution will not be zero, we know that the optimal solution is not a corner solution. Thus, standard first-order conditions (equalities) are necessary conditions for the optimal solution.

The first order conditions to the household's optimization problem set above can be obtained as follows. After using the constraint $n_{t_{0}+j}^{s}+\ell_{t_{0}+j}=1$ to substitute $\ell_{t_{0}+j}$ in the objective function, we can write the Lagrangean to the household's optimization problem as

$$
\begin{aligned}
& L= E_{t_{0}}\left[\sum_{j=0}^{j=\infty} \beta^{j} u\left(c_{t_{0}+j}, 1-n_{t_{0}+j}^{s}\right)\right]+ \\
&+E_{t_{0}}\left[\sum _ { j = 0 } ^ { j = \infty } \beta ^ { j } \lambda _ { t _ { 0 } + j } \left[w_{t_{0}+j} n_{t_{0}+j}^{s}+\sum_{f=1}^{f=F} z_{t_{0}+j}^{f} \pi_{t_{0}+j}^{f}+\sum_{f=1}^{f=F} z_{t_{0}+j}^{f} q_{t_{0}+j}^{f}+\frac{b_{t_{0}+1+j}}{1+r_{t_{0}+j}}\right.\right. \\
&\left.\left.\quad-c_{t_{0}+j}-b_{t_{0}+j}-\sum_{f=1}^{f=F} z_{t_{0}+1+j}^{f} q_{t_{0}+j}^{f}\right]\right]
\end{aligned}
$$

Here, $\lambda_{t_{0}+j}$ is the current value Lagrangean multiplier. $\beta^{j} \lambda_{t_{0}+j}$ is the present value multiplier, i.e., the current value multiplier discounted from period $\left(t_{0}+j\right)$ to period $t_{0}$.

The first-order conditions are:

$$
\begin{aligned}
\frac{\partial L}{\partial c_{t_{0}+j}} & =E_{t_{0}}\left[\beta^{j} u_{1}\left(c_{t_{0}+j}, 1-n_{t_{0}+j}^{s}\right)\right]-E_{t_{0}}\left[\beta^{j} \lambda_{t_{0}+j}\right]=0 \\
\frac{\partial L}{\partial n_{t_{0}+j}^{s}} & =(-1) E_{t_{0}}\left[\beta^{j} u_{2}\left(c_{t_{0}+j}, 1-n_{t_{0}+j}^{s}\right)\right]+E_{t_{0}}\left[\beta^{j} \lambda_{t_{0}+j} w_{t_{0}+j}\right]=0 \\
\frac{\partial L}{\partial b_{t_{0}+1+j}} & =E_{t_{0}}\left[\beta^{j} \lambda_{t_{0}+j} \frac{1}{1+r_{t_{0}+j}}\right]-E_{t_{0}}\left[\beta^{j+1} \lambda_{t_{0}+1+j}\right]=0 \\
\frac{\partial L}{\partial z_{t_{0}+1+j}^{f}} & =E_{t_{0}}\left[\beta^{j} \lambda_{t_{0}+j}\left(-q_{t_{0}+j}^{f}\right)\right]+
\end{aligned}
$$




$$
\begin{gathered}
+E_{t_{0}}\left[\beta^{j+1} \lambda_{t_{0}+1+j}\left(\pi_{t_{0}+1+j}^{f}+q_{t_{0}+1+j}^{f}\right)\right]=0 \\
\frac{\partial L}{\partial \lambda_{t_{0}+j}}=E_{t_{0}}\left[\beta ^ { j } \lambda _ { t _ { 0 } + j } \left[w_{t_{0}+j} n_{t_{0}+j}^{s}+\sum_{f=1}^{f=F} z_{t_{0}+j}^{f} \pi_{t_{0}+j}^{f}+\sum_{f=1}^{f=F} z_{t_{0}+j}^{f} q_{t_{0}+j}^{f}+\frac{b_{t_{0}+1+j}}{1+r_{t_{0}+j}}\right.\right. \\
\left.\left.-c_{t_{0}+j}-b_{t_{0}+j}-\sum_{f=1}^{f=F} z_{t_{0}+1+j}^{f} q_{t_{0}+j}^{f}\right]\right]=0
\end{gathered}
$$

$$
\text { for } j=0,1,2,3, \ldots
$$

In the appendix, we derive the first order conditions of the household's problem in an intuitive way. It is easy to see that the conditions derived using the Lagrangean are the same as the ones we obtain intuitively.

Another easy way of obtaining the first order conditions using mathematics consists in using the two constraints to substitute $c_{t_{0}+j}$ and $n_{t_{0}+j}^{s}$ in the objective function and then take derivatives of the objective function with respect to the remaining decision variables.

We have already explained that equations 4-8 are necessary for an optimum. Since the function $u(.,$.$) is concave, the weights \beta^{j}$ are positive, and $E_{t_{0}}[$.$] is a linear operator which will be applied to$ a reality whose events occur with positive probability, we can conclude that the objective function is also concave. Therefore, equations 4-8 are also sufficient for a maximum.

Since it is not possible, in general, to obtain an explicit solution to the household's optimization problem, we take equations 4-8 as representing this solution (because these equations represent the solution in an implicit way). The optimal solution includes, among other values, values for period $t_{0}: c_{t_{0}}, \ell_{t_{0}}, n_{t_{0}}^{s}, b_{t_{0}+1}, z_{t_{0}+1}^{f}$.

We can conclude that equations 4-8 give, in an implicit way, the household's demand and supply functions for period $t_{0}\left(c_{t_{0}}, b_{t_{0}+1}, z_{t_{0}+1}^{f}\right.$ and $\left.n_{t_{0}}^{s}\right)$ as well as planned demand and supply functions for all future periods. The demand and supply functions for period $t_{0}$ will depend on the current values of the various prices (real wage, real interest rate and price of shares in real terms), on the expectations of the household about the future, on initial holdings of shares and on the household's initial debt position. 


\section{The market clearing conditions}

We have seen that equations 2 and 3 give us, in an implicit way, the typical firm's demand and supply functions for period $t_{0}\left(n_{t_{0}}^{d}, i_{t_{0}}\right.$ and $\left.y_{t_{0}}\right)$. Because all firms are identical and all experience the same value of the technological parameter, the demand and supply functions are the same for every firm. We have also seen that equations 4-8 give us, in an implicit way, the typical household's demand and supply functions for period $t_{0}\left(c_{t_{0}}, b_{t_{0}+1}, z_{t_{0}+1}^{p}\right.$ and $\left.n_{t_{0}}^{s}\right)$. Since all households are identical, the demand and supply functions are the same for every household. Thus, with $\mathrm{H}$ homogeneous households and $\mathrm{F}$ homogeneous firms, the market clearing conditions for period $t_{0}$ are:

( i ) In the goods market, the amount of consumption demanded by the $\mathrm{H}$ households plus the amount of investment demanded by the F firms must be equal to the amount of output supplied by the F firms:

$$
\begin{gathered}
\sum_{h=1}^{h=H} c_{t_{0}}+\sum_{f=1}^{f=F} i_{t_{0}}=\sum_{f=1}^{f=F} y_{t_{0}} \Leftrightarrow \\
\Leftrightarrow H c_{t_{0}}+F\left[k_{t_{0}+1}-(1-\delta) k_{t_{0}}\right]=F A_{t_{0}} F\left(k_{t_{0}}, n_{t_{0}}^{d}\right) \\
\Leftrightarrow c_{t_{0}}+\frac{F}{H}\left[k_{t_{0}+1}-(1-\delta) k_{t_{0}}\right]=\frac{F}{H} A_{t_{0}} F\left(k_{t_{0}}, n_{t_{0}}^{d}\right)
\end{gathered}
$$

( ii ) In the labour market, the number of "hours of work" supplied by the H households must be equal to the number of "hours of work" demanded by the F firms:

$$
\begin{gathered}
\sum_{h=1}^{h=H} n_{t_{0}}^{s}=\sum_{f=1}^{f=F} n_{t_{0}}^{d} \Leftrightarrow H n_{t_{0}}^{s}=F n_{t_{0}}^{d} \Leftrightarrow \\
\Leftrightarrow n_{t_{0}}^{s}=\frac{F}{H} n_{t_{0}}^{d}
\end{gathered}
$$

( iii ) Let us now examine the loans market. If an household borrows from another household, we have positive borrowing on the part of the first household and negative borrowing in the same 
amount on the part of the other household. The sum of the two households' debt positions is therefore equal to zero. Combining this observation with the fact that we only have households borrowing and lending in this economy makes it easy to conclude that the sum all households' debt positions must necessarily be equal to zero. Therefore, we can write:

$$
\begin{gathered}
\sum_{h=1}^{h=H} \frac{b_{t_{0}+1}}{1+r_{t_{0}}}=0 \Leftrightarrow H \frac{b_{t_{0}+1}}{1+r_{t_{0}}}=0 \Leftrightarrow \\
\Leftrightarrow b_{t_{0}+1}=0
\end{gathered}
$$

This means that, in equilibrium, the typical household will neither borrow from nor lend to other households (this is the usual result with homogeneous households).

(iv ) In the shares market, the market clearing condition is that each firm should be completely held. In other words: the sum of the shares of each firm $\mathrm{f}$ held by the $\mathrm{H}$ households must be equal to $100 \%$

$$
\begin{gathered}
\sum_{h=1}^{h=H} z_{t_{0}+1}^{f}=1 \Leftrightarrow H z_{t_{0}+1}^{f}=1 \Leftrightarrow \\
\Leftrightarrow z_{t_{0}+1}^{f}=\frac{1}{H}
\end{gathered}
$$

$$
\text { for } \mathrm{f}=1,2,3, \ldots, \mathrm{F}
$$

\section{The competitive equilibrium}

At $t_{0}$, the competitive equilibrium assuming $\mathrm{H}$ homogeneous households and $\mathrm{F}$ homogeneous firms is a system which includes 
A) The first-order conditions of the typical household's optimization problem (which give, in an implicit way, the household's demand and supply functions $\left.{ }^{8}\right)$. These are given by equations $4-8$.

B) The first-order conditions for the typical firm's optimization problem (which give, in an implicit way, the firm's demand and supply functions $\left.{ }^{9}\right)$. These are given by equations 2 and 3 C) The market-clearing conditions in period $t_{0}$ for all markets. These are given by equations $9-12$

Putting together A), B) and C), the system we obtain is

$$
\begin{aligned}
& E_{t_{0}}\left[\beta^{j} u_{1}\left(c_{t_{0}+j}, 1-n_{t_{0}+j}^{s}\right)\right]=E_{t_{0}}\left[\beta^{j} \lambda_{t_{0}+j}\right] \\
& E_{t_{0}}\left[\beta^{j} u_{2}\left(c_{t_{0}+j}, 1-n_{t_{0}+j}^{s}\right)\right]=E_{t_{0}}\left[\beta^{j} \lambda_{t_{0}+j} w_{t_{0}+j}\right] \\
& E_{t_{0}}\left[\beta^{j} \lambda_{t_{0}+j} \frac{1}{1+r_{t_{0}+j}}\right]=E_{t_{0}}\left[\beta^{j+1} \lambda_{t_{0}+1+j}\right] \\
& E_{t_{0}}\left[\beta^{j} \lambda_{t_{0}+j} q_{t_{0}+j}^{f}\right]=E_{t_{0}}\left[\beta^{j+1} \lambda_{t_{0}+1+j}\left(\pi_{t_{0}+1+j}^{f}+q_{t_{0}+1+j}^{f}\right)\right] \\
& E_{t_{0}}\left[\beta ^ { j } \lambda _ { t _ { 0 } + j } \left[w_{t_{0}+j} n_{t_{0}+j}^{s}+\sum_{f=1}^{f=F} z_{t_{0}+j}^{f} \pi_{t_{0}+j}^{f}+\sum_{f=1}^{f=F} z_{t_{0}+j}^{f} q_{t_{0}+j}^{f}+\frac{b_{t_{0}+1+j}}{1+r_{t_{0}+j}}\right.\right. \\
& \left.\left.-c_{t_{0}+j}-b_{t_{0}+j}-\sum_{f=1}^{f=F} z_{t_{0}+1+j}^{f} q_{t_{0}+j}^{f}\right]\right]=0 \\
& E_{t_{0}}\left[\frac{A_{t_{o}+j} F_{2}\left(k_{t_{0}+j,} n_{t_{0}+j}^{d}\right)}{\left(1+r_{t_{0}}\right) \ldots\left(1+r_{t_{0}-1+j}\right)}\right]=E_{t_{0}}\left[\frac{w_{t_{0}+j}}{\left(1+r_{t_{0}}\right) \ldots\left(1+r_{t_{0}-1+j}\right)}\right] \\
& E_{t_{0}}\left[\frac{A_{t_{o}+1+j} F_{1}\left(k_{t_{0}+1+j}, n_{t_{0}+1+j}^{d}\right)+(1-\delta)}{\left(1+r_{t_{0}}\right) \ldots\left(1+r_{t_{0}-1+j}\right)\left(1+r_{t_{0}+j}\right)}\right]=
\end{aligned}
$$

${ }^{8}$ We should include one set of first-order conditions for each household. However, because households are all equal, the set of first-order conditions is the same for all households. Hence, we only have to write it once. Otherwise we would have a system with repeated equations (i.e., redundant equations).

${ }^{9}$ We should include one set of first-order conditions for each firm. However, because firms are all equal, the set of first-order conditions is the same for all firms. Hence, we only have to write it once. Otherwise we would have a system with repeated equations (i.e., redundant equations). 


$$
\begin{aligned}
=E_{t_{0}}\left[\frac{1}{\left(1+r_{t_{0}}\right) \ldots\left(1+r_{t_{0}-1+j}\right)}\right] & \\
c_{t_{0}}+\frac{F}{H}\left[k_{t_{0}+1}-(1-\delta) k_{t_{0}}\right] & =\frac{F}{H} A_{t_{0}} F\left(k_{t_{0}}, n_{t_{0}}^{d}\right) \\
n_{t_{0}}^{s} & =\frac{F}{H} n_{t_{0}}^{d} \\
b_{t_{0}+1} & =0 \\
z_{t_{0}+1}^{f} & =\frac{1}{H} \\
\pi_{t_{0}+j}^{f}=A_{t_{0}+j} F\left(k_{t_{0}+j}, n_{t_{0}+j}^{d}\right)-w_{t_{0}+j} n_{t_{0}+j}^{d}-\left[k_{t_{0}+1+j}-(1-\delta) k_{t_{0}+j}\right] & \text { for } j=0,1,2,3, \ldots
\end{aligned}
$$

Equation 23 is the definition of profits of firm $\mathrm{f}$ in period $\left(t_{0}+j\right)$. To complete this system, we have to add the initial condition on the firm's capital stock $\left(k_{t_{0}}\right)$ and the transversality condition on the firm's capital stock given by equation 1 .

\section{The competitive equilibrium assuming Rational Expecta-}

\section{tions}

We are interested in the Rational Expectations equilibrium. The Rational Expectations way of solving the "problem of expectations" ${ }^{10}$ consists in assuming that the expectations about economic

\footnotetext{
${ }^{10} \mathrm{By}$ "the problem of expectations" we mean the fact that the solution of the system given by equations 1323 requires some way of computing the expected values of several variables in that system. To assume Rational Expectations is perhaps the easiest acceptable way of solving this problem.

The dependence of the current equilibrium on the expectations of economic agents about the future is a key feature of the model and is easy to understand. For example, if households expect the real wage to increase significantly within 5 periods, they will probably wish to work less and borrow more today because the reward of working within 5 periods is greater and, therefore, they can work more and pay their debts in those later periods.
} 
variables in periods $\left(t_{0}+1\right),\left(t_{0}+2\right),\left(t_{0}+3\right), \ldots$ are formed by economic agents by assuming that the value of these variables will be the outcome of a Competitive Equilibrium in each future period. In other words, economic agents assume that:

- the value of economic variables in period $\left(t_{0}+1\right)$ will be the solution to a system like 13-23 but with $t_{0}$ replaced by $\left(t_{0}+1\right)$;

- the value of economic variables in period $\left(t_{0}+2\right)$ will be the solution to a system like 13-23 but with $t_{0}$ replaced by $\left(t_{0}+2\right)$;

- the value of economic variables in period $\left(t_{0}+3\right)$ will be the solution to a system like 13-23 but with $t_{0}$ replaced by $\left(t_{0}+3\right)$;

This means that to represent the Rational Expectations equilibrium, we have to take into account equations 13-23 not only in period $t_{0}$, but also in periods $\left(t_{0}+1\right),\left(t_{0}+2\right),\left(t_{0}+3\right), \ldots$ . Therefore, the Rational Expectations Equilibrium can be written as a system like 13-23 where instead of $t_{0}$ we will write $t$ and then emphasize that $t=t_{0},\left(t_{0}+1\right),\left(t_{0}+2\right),\left(t_{0}+3\right), \ldots$

$$
\begin{aligned}
& E_{t}\left[\beta^{j} u_{1}\left(c_{t+j}, 1-n_{t+j}^{s}\right)\right]=E_{t}\left[\beta^{j} \lambda_{t+j}\right] \\
& E_{t}\left[\beta^{j} u_{2}\left(c_{t+j}, 1-n_{t+j}^{s}\right)\right]=E_{t}\left[\beta^{j} \lambda_{t+j} w_{t+j}\right] \\
& E_{t}\left[\beta^{j} \lambda_{t+j} \frac{1}{\left.1+r_{t+j}\right]}=E_{t}\left[\beta^{j+1} \lambda_{t+1+j}\right]\right.=E_{t}\left[\beta^{j+1} \lambda_{t+1+j}\left(\pi_{t+1+j}^{p}+q_{t+1+j}^{p}\right)\right] \\
& E_{t}\left[\beta^{j} \lambda_{t+j} q_{t+j}^{p}\right] \\
& E_{t}\left[\beta ^ { j } \lambda _ { t + j } \left[w_{t+j} n_{t+j}^{s}+\sum_{f=1}^{f=F} z_{t+j}^{f} \pi_{t+j}^{f}+\sum_{f=1}^{f=F} z_{t+j}^{f} q_{t+j}^{f}+\frac{b_{t+1+j}}{1+r_{t+j}}\right.\right. \\
&\left.-c_{t+j}-b_{t+j}-\sum_{f=1}^{f=F} z_{t+1+j}^{f} q_{t+j}^{f}\right] \\
& E_{t}\left[\frac{A_{t+j} F_{2}\left(k_{t+j}, n_{t+j}^{d}\right)}{\left(1+r_{t}\right) \ldots\left(1+r_{t-1+j}\right)}\right]=E_{t}\left[\frac{w_{t+j}}{\left(1+r_{t}\right) \ldots\left(1+r_{t-1+j}\right)}\right] \\
& E_{t}\left[\frac{A_{t+1+j} F_{1}\left(k_{t+1+j,} n_{t+1+j}^{d}\right)+(1-\delta)}{\left(1+r_{t}\right) \ldots\left(1+r_{t-1+j}\right)\left(1+r_{t+j}\right)}\right]=E_{t}\left[\frac{1}{\left(1+r_{t}\right) \ldots\left(1+r_{t-1+j}\right)}\right]
\end{aligned}
$$




$$
\begin{aligned}
& c_{t}+\frac{P}{H}\left[k_{t+1}-(1-\delta) k_{t}\right]=\frac{P}{H} A_{t} F\left(k_{t}, n_{t}^{d}\right) \\
& n_{t}^{s}=\frac{P}{H} n_{t}^{d} \\
& b_{t+1}=0 \\
& z_{t+1}^{p}=\frac{1}{H} \\
& \pi_{t+j}^{p}=A_{t+j} F\left(k_{t+j}, n_{t+j}^{d}\right)-w_{t+j} n_{t+j}^{d}-\left[k_{t+1+j}-(1-\delta) k_{t+j}\right] \\
& \text { for } \quad t=t_{0},\left(t_{0}+1\right),\left(t_{0}+2\right), \ldots \\
& \text { and for } \quad j=0,1,2,3, \ldots
\end{aligned}
$$

To complete this system, we have to add the initial condition on the firm's capital stock $\left(k_{t_{0}}\right)$ and the transversality condition on the firm's capital stock given by equation 1 .

In particular, these equations are valid for $j=0$

$$
\begin{aligned}
& u_{1}\left(c_{t}, 1-n_{t}^{s}\right)=\lambda_{t} \\
& u_{2}\left(c_{t}, 1-n_{t}^{s}\right)=\lambda_{t} w_{t} \\
& \frac{\lambda_{t}}{1+r_{t}}=\beta E_{t}\left[\lambda_{t+1}\right] \\
& \lambda_{t} q_{t}^{f}=\beta E_{t}\left[\lambda_{t+1}\left(\pi_{t+1}^{f}+q_{t+1}^{f}\right)\right] \\
& \lambda_{t}\left[w_{t} n_{t}^{s}+\sum_{f=1}^{f=F} z_{t}^{f} \pi_{t}^{f}+\sum_{f=1}^{f=F} z_{t}^{f} q_{t}^{f}+\frac{b_{t+1}}{1+r_{t}}-c_{t}-b_{t}-\sum_{f=1}^{f=F} z_{t+1}^{f} q_{t}^{f}\right]=0 \\
& A_{t} F_{2}\left(k_{t}, n_{t}^{d}\right)=w_{t} \\
& E_{t}\left[\frac{A_{t+1} F_{1}\left(k_{t+1}, n_{t+1}^{d}\right)+(1-\delta)}{1+r_{t}}\right]=1
\end{aligned}
$$




$$
\begin{gathered}
c_{t}+\frac{F}{H}\left[k_{t+1}-(1-\delta) k_{t}\right]=\frac{F}{H} A_{t} F\left(k_{t}, n_{t}^{d}\right) \\
n_{t}^{s}=\frac{F}{H} n_{t}^{d} \\
b_{t+1}=0 \\
z_{t+1}^{f}=\frac{1}{H} \\
\pi_{t}^{f}=A_{t} F\left(k_{t}, n_{t}^{d}\right)-w_{t} n_{t}^{d}-\left[k_{t+1}-(1-\delta) k_{t}\right] \\
\text { for } \quad t=t_{0},\left(t_{0}+1\right),\left(t_{0}+2\right), \ldots
\end{gathered}
$$

Assuming Certainty Equivalence ${ }^{11}$, we obtain

$$
u_{1}\left(c_{t}, 1-n_{t}^{s}\right)=\lambda_{t}
$$

$$
u_{2}\left(c_{t}, 1-n_{t}^{s}\right)=\lambda_{t} w_{t}
$$

$$
\frac{\lambda_{t}}{1+r_{t}}=\beta E_{t}\left[\lambda_{t+1}\right]
$$

$$
\lambda_{t} q_{t}^{f}=\beta E_{t}\left[\lambda_{t+1}\right]\left[E\left[\pi_{t+1}^{f}\right]+E_{t}\left[q_{t+1}^{f}\right]\right]
$$

\footnotetext{
${ }^{11}$ The argument of Certainty Equivalence runs as follows. Suppose, as an example, that we have a function $g\left(k_{t+1}, n_{t+1}\right)$. If we expand $g$ around the expected values of its variables, we obtain $g\left(k_{t+1}, n_{t+1}\right) \simeq$ $g\left[E_{t}\left(k_{t+1}\right), E_{t}\left(n_{t+1}\right)\right]+\left[k_{t+1}-E_{t}\left(k_{t+1}\right)\right] g_{1}\left[E_{t}\left(k_{t+1}\right), E_{t}\left(n_{t+1}\right)\right]+\left[n_{t+1}-E_{t}\left(n_{t+1}\right)\right] g_{2}\left[E_{t}\left(k_{t+1}\right), E_{t}\left(n_{t+1}\right)\right]$.

Taking expectations on both sides of this equation, we obtain

$E_{t}\left[g\left(k_{t+1}, n_{t+1}\right)\right] \simeq g\left[E_{t}\left(k_{t+1}\right), E_{t}\left(n_{t+1}\right)\right]$

This is the result we are going to use to simplify the equations.

To assume Certainty Equivalence is a standard practice in the literature because it is a good way of obtaining a system which can easily be solved numerically.
} 


$$
\begin{gathered}
w_{t} n_{t}^{s}+\sum_{f=1}^{f=F} z_{t}^{f} \pi_{t}^{f}+\sum_{f=1}^{f=F} z_{t}^{f} q_{t}^{f}+\frac{b_{t+1}}{1+r_{t}}-c_{t}-b_{t}-\sum_{f=1}^{f=F} z_{t+1}^{f} q_{t}^{f}=0 \\
A_{t} F_{2}\left(k_{t}, n_{t}^{d}\right)=w_{t} \\
\frac{E_{t}\left[A_{t+1}\right] F_{1}\left(k_{t+1}, E_{t}\left[n_{t+1}^{d}\right]\right)+(1-\delta)}{1+r_{t}}=1 \\
c_{t}+\frac{F}{H}\left[k_{t+1}-(1-\delta) k_{t}\right]=\frac{F}{H} A_{t} F\left(k_{t}, n_{t}^{d}\right) \\
n_{t}^{s}=\frac{F}{H} n_{t}^{d} \\
\pi_{t}^{f}=A_{t} F\left(k_{t}, n_{t}^{d}\right)-w_{t} n_{t}^{d}-\left[k_{t+1}-(1-\delta) k_{t}\right] \\
t=t_{0},\left(t_{0}+1\right),\left(t_{0}+2\right), \ldots \\
b_{t+1}=0 \\
z_{t+1}^{f}=\frac{1}{H} \\
\end{gathered}
$$

Note that $k_{t+1}$ is chosen by the firm in period t.

\section{Walras' Law}

Substituting the market clearing condition in the labour market (equation 56), the market clearing condition in the loans market (equation 57) and the market clearing condition in the shares market (equation 58) into the household's budget constraint (equation 52), we obtain

$$
w_{t} \frac{F}{H} n_{t}^{d}+\sum_{f=1}^{f=F} z_{t}^{f} \pi_{t}^{f}+\sum_{f=1}^{f=F} z_{t}^{f} q_{t}^{f}=c_{t}+b_{t}+\sum_{f=1}^{f=F} \frac{1}{H} q_{t}^{f}
$$

Assuming that the loans market and the shares market were in equilibrium in period $(t-1)$ so that $b_{t}=0$ and $z_{t}^{f}=\frac{1}{H}$, we obtain 


$$
w_{t} \frac{F}{H} n_{t}^{d}+\frac{F}{H} \pi_{t}^{f}-c_{t}=0
$$

Using equation 59 this last equation becomes

$$
\frac{F}{H} A_{t} F\left(k_{t}, n_{t}^{d}\right)-\frac{F}{H}\left[k_{t+1}-(1-\delta) k_{t}\right]-c_{t}=0
$$

which is the same as equation 55 . In short, starting from equation 52 we have obtained equation 55. This means that the two equations are redundant. Therefore, we can drop one of the two equations $^{12}$. In the system which follows, we shall drop equation 52.

\section{The second welfare theorem}

With a production function that is homogeneous of degree one, it follows that $\frac{F}{H} A_{t} F\left(k_{t}, n_{t}^{d}\right)=$ $A_{t} F\left(\frac{F}{H} k_{t}, \frac{F}{H} n_{t}^{d}\right)$. Also, if the production function is homogeneous of degree one, then its partial derivatives will be homogeneous of degree zero. From this it follows that $A_{t} F_{2}\left(k_{t}, n_{t}^{d}\right)=$ $A_{t} F_{2}\left(\frac{F}{H} k_{t}, \frac{F}{H} n_{t}^{d}\right)$ and that $E_{t}\left[A_{t+1}\right] F_{1}\left(k_{t+1}, E_{t}\left[n_{t+1}^{d}\right]\right)=E_{t}\left[A_{t+1}\right] F_{1}\left(\frac{F}{H} k_{t+1}, \frac{F}{H} E_{t}\left[n_{t+1}^{d}\right]\right)$. If we use these results and then define the following new variables

$$
\bar{k}_{t}=\frac{F}{H} k_{t}, \bar{n}_{t}^{d}=\frac{F}{H} n_{t}^{d}, \bar{\pi}_{t}^{f}=\frac{F}{H} \pi_{t}^{f}, \bar{q}_{t}^{f}=\frac{F}{H} q_{t}^{f},
$$

we can write the system describing the competitive equilibrium with $\mathrm{H}$ homogeneous households and $\mathrm{F}$ homogeneous firms plus Rational Expectations as

$$
\begin{gathered}
u_{1}\left(c_{t}, 1-n_{t}^{s}\right)=\lambda_{t} \\
u_{2}\left(c_{t}, 1-n_{t}^{s}\right)=\lambda_{t} w_{t}
\end{gathered}
$$

\footnotetext{
${ }^{12}$ This result corresponds to Walras' Law.
} 


$$
\lambda_{t}=\beta E_{t}\left[\lambda_{t+1}\right]\left(1+r_{t}\right)
$$

$$
\lambda_{t} \bar{q}_{t}^{f}=\beta E_{t}\left[\lambda_{t+1}\right]\left(E_{t}\left[\bar{\pi}_{t+1}^{f}\right]+E_{t}\left[\bar{q}_{t+1}^{f}\right]\right)
$$

$$
\begin{gathered}
A_{t} F_{2}\left(\bar{k}_{t}, \bar{n}_{t}^{d}\right)=w_{t} \\
E_{t}\left[A_{t+1}\right] F_{1}\left(\bar{k}_{t+1}, E_{t}\left[\bar{n}_{t+1}^{d}\right]\right)+(1-\delta)=1+r_{t} \\
c_{t}+\left[\bar{k}_{t+1}-(1-\delta) \bar{k}_{t}\right]=A_{t} F\left(\bar{k}_{t}, \bar{n}_{t}^{d}\right)
\end{gathered}
$$

$$
n_{t}^{s}=\bar{n}_{t}^{d}
$$

$$
b_{t+1}=0
$$

$$
z_{t+1}^{f}=\frac{1}{H}
$$

$$
\bar{\pi}_{t}^{f}=A_{t} F\left(\bar{k}_{t}, \bar{n}_{t}^{d}\right)-w_{t} \bar{n}_{t}^{d}-\left[\bar{k}_{t+1}-(1-\delta) \bar{k}_{t}\right]
$$




$$
\text { for } \quad t=t_{0},\left(t_{0}+1\right),\left(t_{0}+2\right),\left(t_{0}+3\right), \ldots
$$

Equation 70 is the definition of profits of firm $\mathrm{f}$ multiplied on both sides by $\frac{F}{H}$. We have one exogenous variable $\left(A_{t}\right)$ and 11 endogenous variables: $c_{t}, n_{t}^{s}, \lambda_{t}, w_{t}, r_{t}, \bar{q}_{t}^{f}, \bar{\pi}_{t}^{f}, b_{t+1}, \bar{k}_{t}, \bar{n}_{t}^{d}$ and $z_{t+1}^{f}$.

Note that $c_{t}, n_{t}^{s}, b_{t+1}$ and $z_{t+1}^{f}$ are per-household values (per capita values). Since $k_{t}, n_{t}^{d}$ and $\pi_{t}$ are per-firm values, $\bar{k}_{t}, \bar{n}_{t}^{d}$ and $\bar{\pi}_{t}^{f}$ are per capita values.

Let us now show that this model is a zero growth version of the model in King, Plosser and Rebelo (1988a). Equation 60 can be written as

$$
u_{1}\left(c_{t}, 1-n_{t}^{s}\right)-\lambda_{t}=0
$$

Using 67 to substitute $\bar{n}_{t}^{d}$ in 64 and then using the resulting equation to substitute $w_{t}$ in 61 and then rearranging the equation, we obtain

$$
u_{2}\left(c_{t}, 1-n_{t}^{s}\right)-\lambda_{t} A_{t} F_{2}\left(\bar{k}_{t}, n_{t}^{s}\right)=0
$$

Using 62 to substitute $\left(1+r_{t}\right)$ in 65 and then using 67 to substitute $\bar{n}_{t+1}^{d}$ in the same equation and then rearranging the equation, we obtain

$$
\beta E_{t}\left[\lambda_{t+1}\right]\left[E_{t}\left[A_{t+1}\right] F_{1}\left(\bar{k}_{t+1}, E_{t}\left[n_{t+1}^{s}\right]\right)+(1-\delta)\right]-\lambda_{t}=0
$$

Using equation 67 to substitute $\bar{n}_{t}^{d}$ in equation 66 and then rearranging the equation, we obtain

$$
A_{t} F\left(\bar{k}_{t}, n_{t}^{s}\right)+(1-\delta) \bar{k}_{t}-\bar{k}_{t+1}-c_{t}=0
$$

Let us now look at equations (2.11)-(2.15) in the King, Plosser and Rebelo (1988a) paper (page 203). If we set $\gamma_{X}=1$ in equations (2.11)-(2.14), we obtain the same set of equations as the set of equations given by 71-74. Taking equation 60 into account it is easy to see that equation (2.15) in their model is just another way of writing the same as we have written in equation 1 (the transversality condition on the firm's capital stock). 
Since $\gamma_{X}$ corresponds to one plus the rate of growth in their model, $\gamma_{X}=1$ means zero growth. This proves that our model is a zero growth version of their model.

We can summarize as follows. We developed our model in a decentralized way whereas King, Plosser and Rebelo solve their model as a central planner's problem. We have shown that setting the rate of growth to zero in their model produces the same set of equations as the ones we obtained. Hence our claim that the model in this chapter is a decentralized zero growth version of their model.

The fact that we have used a decentralized approach and arrived at the same equations as King, Plosser and Rebelo - who have used a central planner's approach - is a proof of the second welfare theorem. It proves that in the context of the set of assumptions we are using the second welfare theorem holds.

\section{Near steady-state dynamics}

We are interested in studying the behaviour of the system 71-74 around its steady-state. A steadystate is a dynamic equilibrium in which the level of each variable grows at some constant rate (different variables can grow at different rates). In the context of the model we have at hand, if we assume $A_{t}=A \forall t$, imposing a constant rate of growth for every variable implies zero rate of growth for all variables (i.e., it implies that all variables must be constant). To prove this we proceed as follows. With $A_{t}=A \forall t$, we have a non-stochastic situation. Therefore, we can drop the expectations operator. Since the endowment of time per household is bounded, $n_{t}^{s}$ cannot grow in a steady-state. Hence, a steady-state must be such that $n_{t}^{s}=n^{s}, \forall t$. From equation 67 it follows that $\bar{n}_{t}^{d}$ must also be constant in the steady-state. In other words, in the steady-state we will also have $\bar{n}_{t}^{d}=\bar{n}^{d}, \forall t$. Taking this into account and assuming that the real interest rate is constant in the steady-state, equation 65 in the steady-state can be written as

$$
A F_{1}\left(\bar{k}_{t+1}, \bar{n}^{d}\right)+(1-\delta)=1+r
$$

This implies that $\bar{k}_{t+1}$ must be constant in the steady-state. In other words, a steady-state must be such that $\bar{k}_{t+1}=\bar{k}, \forall t$. Note that, given the definition of $\bar{k}_{t}$, this means constant stock of 
capital per capita.

Therefore, equation 66 in the steady-state will be

$$
c_{t}+[\bar{k}-(1-\delta) \bar{k}]=A F\left(\bar{k}, \bar{n}^{d}\right)
$$

This implies $c_{t}=c, \forall t$.

From this it follows that equation 60 in the steady-state will be

$$
u_{1}\left(c, 1-n^{s}\right)=\lambda_{t}
$$

This implies $\lambda_{t}=\lambda, \forall t$.

Hence, this model's steady-state is one where all variables are constant. The conclusion to be drawn is that, in the present model, a quick way of obtaining the steady-state is as follows: $(i)$ take the system 71-74 with specific utility and production functions; (ii) set $A_{t}=A, A_{t+1}=A$, $c_{t}=c, n_{t}^{s}=n^{s}, n_{t+1}^{s}=n^{s}, \lambda_{t}=\lambda, \lambda_{t+1}=\lambda, \bar{k}_{t}=\bar{k}$ and $\bar{k}_{t+1}=\bar{k}$ in the resulting system; (iii) solve for $c, n^{s}, \bar{k}, \lambda$.

The specific utility and production functions we will use in this paper are as follows:

$$
\begin{gathered}
u\left(c_{t}, \ell_{t}\right)=\ln c_{t}+\phi \ln \ell_{t} \\
A_{t} F\left(k_{t}, n_{t}^{d}\right)=A_{t}\left(k_{t}\right)^{1-\alpha}\left(n_{t}^{d}\right)^{\alpha}
\end{gathered}
$$

With these specific utility and production functions the steady-state values we obtain are

$$
\begin{gathered}
\bar{k}=\frac{(\alpha / \phi) A\left[\frac{1}{\beta(1-\alpha) A}+\frac{\delta-1}{(1-\alpha) A}\right]^{\frac{\alpha-1}{\alpha}}}{(\alpha / \phi) A\left[\frac{1}{\beta(1-\alpha) A}+\frac{\delta-1}{(1-\alpha) A}\right]+\frac{1}{\beta(1-\alpha)}+\frac{\delta-1}{1-\alpha}-\delta} \\
n^{s}=\left[\frac{1}{\beta(1-\alpha) A}+\frac{\delta-1}{(1-\alpha) A}\right]^{\frac{1}{\alpha}} \bar{k} \\
c=\left(1-n^{s}\right)(\alpha / \phi) A(\bar{k})^{1-\alpha}\left(n^{s}\right)^{\alpha-1} \\
\lambda=\frac{1}{c}
\end{gathered}
$$


We want to examine the dynamics of the system 71-74 around its steady-state ${ }^{13}$. Therefore, we log-linearize each of the four equations around the steady-state values $\left(c, n^{s}, \lambda, \bar{k}\right)$. To make the system deviate from the steady-state we use technological shocks ${ }^{14}$.

Given a sequence of technological shocks which make $A_{t}$ deviate from $A$, we can apply the King, Plosser and Rebelo (1988) method on the log-linearized system of equations 71-74 to obtain the percentage deviations of $c_{t}, n_{t}^{s}, \lambda_{t}$ and $\bar{k}_{t}$ from their steady-state values. Using these solutions, we can then use the log-linearized version of equation 67 to obtain the percentage deviation of $\bar{n}_{t}^{d}$ from its steady-state value; use the log-linearized production function to obtain the percentage deviation of physical output from its steady-state value; use the log-linearized capital accumulation equation to obtain the percentage deviation of investment from its steady-state value; use the log-linearized version of equation 64 to obtain the real wage percentage deviation from its steady-state; use the log-linearized version of equation 62 to obtain the real interest rate percentage deviation from its steady-state; and use the log-linearized version of equation 63 and the log-linearized version of equation 70 to obtain the percentage deviation of the real price of shares from its steady-state. Equations 68 and 69 tell us that $b_{t+1}$ and $z_{t+1}$ never deviate from their steady-state values.

Once technological shocks cease (i.e., once $A_{t}$ becomes constant again) the system 71-74 will converge again to a steady-state (which will be the same as the initial steady-state if the value of the technological parameter is the same as the one it started from).

\section{Calibration}

We have already mentioned that, in order to study the dynamic properties of the model, we first loglinearize each of the four equations 71-74 around the steady-state values of its variables $\left(c, n^{s}, \lambda, \bar{k}\right)$. What we obtain is a linear system where instead of each variable appears the percentage deviation of that variable from its steady-state value [for example, instead of $c_{t}$ we have $\hat{c}_{t}=\ln \left(\frac{c_{t}}{c}\right)$ where $c$ is the steady-state value of $c_{t}$ ]. The log-linearized system can then be calibrated as follows. With

\footnotetext{
${ }^{13}$ We don't need to compute the steady-state to obtain the deviations of the various variables from their steadystate values. However, to check the existence of a steady-state, we may want to do it.

${ }^{14}$ In general, any shock to any exogenous variable will make the system deviate from its steady-state.
} 
the specific utility function we are using - equation 75 - we obtain:

\begin{tabular}{|l|l|}
\hline Elasticity of the MU of consumption with respect to consumption & -1 \\
\hline Elasticity of the MU of consumption with respect to leisure & 0 \\
\hline Elasticity of the MU of leisure with respect to consumption & 0 \\
\hline Elasticity of the MU of leisure with respect to leisure & -1 \\
\hline
\end{tabular}

From the U.S.A. data, we obtain

\begin{tabular}{|l|l|l|}
\hline & value & source \\
\hline investment share of output in the steady-state $(i / y)$ & 0.167 & Barro (1993) \\
\hline labour's share of output $(\alpha)$ & 0.58 & King et al. (1988a) \\
\hline labour supply in the steady-state $\left(n^{s}\right)$ & 0.2 & King et al. (1988a) \\
\hline real interest rate in the steady-state $(r)$ & 0.007060 & FRED and Barro \\
\hline
\end{tabular}

As usual, we take the post-war average as representing the steady-state value. The last value in the table is a per-quarter value. It was obtained using data from the Federal Reserve Economic Data (FRED) to compute the average nominal interest rate ${ }^{15}$ for the period 1949-1986 and the data from Barro (1993) to compute the average rate of inflation for the same period. The value obtained for the average nominal interest rate was 0.016383 and the value obtained for the average rate of inflation was 0.009258 .

Using the values in the preceding table we then proceed as follows. First, it is straightforward to conclude that the consumption share of output will be 0.833 . Second, equation 62 in the steady-state can be written as

$$
\begin{aligned}
& \frac{\lambda}{1+r}=\beta \lambda \Leftrightarrow \\
& \Leftrightarrow \beta=\frac{1}{1+r}
\end{aligned}
$$

Since $r=0.007060$, we calibrate

$$
\beta=0.993
$$

Third, the capital accumulation equation in the steady-state is

\footnotetext{
${ }^{15}$ The specific nominal interest rate used was the Bank Prime Loan Rate.
} 


$$
k=(1-\delta) k+i \Leftrightarrow i=\delta k
$$

Therefore, the share of investment will be given by

$$
\frac{i}{y}=\frac{\delta k}{A k^{1-\alpha}\left(n^{d}\right)^{\alpha}} \Leftrightarrow \frac{i}{y}=\frac{\delta}{A k^{-\alpha}\left(n^{d}\right)^{\alpha}} \Leftrightarrow \frac{i}{y}=\frac{\delta(1-\alpha)}{(1-\alpha) A k^{-\alpha}\left(n^{d}\right)^{\alpha}}
$$

Using the Cobb-Douglas production function and equation 81 above, equation 65 in the steadystate can be rearranged to give $(1-\alpha) A k^{-\alpha}\left(n^{d}\right)^{\alpha}=\frac{1}{\beta}-(1-\delta)$. Therefore, we can write

$$
\frac{i}{y}=\frac{\delta(1-\alpha)}{\frac{1}{\beta}-(1-\delta)} \Leftrightarrow \delta=\frac{\frac{i}{y}\left(\frac{1}{\beta}-1\right)}{1-\alpha-\frac{i}{y}}
$$

Hence, we calibrate

$$
\delta=0.0047
$$

We can summarize the new information in a table

\begin{tabular}{|l|l|}
\hline consumption share of output in the steady-state $(c / y)$ & 0.833 \\
\hline household's intertemporal discount factor $(\beta)$ & 0.993 \\
\hline per-quarter rate of depreciation of the capital stock $(\delta)$ & 0.0047 \\
\hline
\end{tabular}

Note that we don't need to calibrate the parameter $\phi$ because it disappears when we do the $\log$-linearization ${ }^{16}$

\section{Response of the model to exogenous shocks}

As already mentioned, the response of the log-linearized model to shocks in the exogenous variables can be obtained using the King, Plosser and Rebelo (1988) method, which is based on Blanchard and Khan (1980). We next present the result of two experiments that use shocks to the technological parameter: an impulse response experiment and a stochastic simulation experiment.

\footnotetext{
${ }^{16}$ To obtain the steady-state values of the four main variables, note that the four equations that give these values [equations77-80], will have $\phi$ as a variable but will have $n^{s}=0.2$ from our calibration. Also, we can set any value we want for the steady-state value of the technological parameter (set $A=1$, for example) because that corresponds to a specific choice of units in terms of measuring physical output.
} 
To do these two experiments, we assume that the technological parameter evolves according to

$$
\hat{A}_{t}=0.9 \hat{A}_{t-1}+\varepsilon_{t}
$$

where $\varepsilon_{t}$ is a white noise ${ }^{17}$.

\subsection{Impulse response}

We first perform an impulse response experiment. Let us suppose that $t_{0}=2$ and use the following steps:

( i ) Assume that at $t=1$ the economy is in its steady-state with $\hat{A}_{1}=0$;

( ii ) Assume that at $t=2$, the shock is $\varepsilon_{2}=0.01$;

( iii ) From equation 82 above it follows that $\hat{A}_{2}=0.01$. And using the same equation we can also compute the expected values of $\hat{A}_{s}$ for $s=3,4,5, \ldots$;

(iv ) Use the values from ( iii ) and the Blanchard and Khan algorithm to obtain the expected path that the "percentage deviation of each variable from its steady state" will take from $t_{0}$ until some point in the future ( 20 quarters ahead, for example ).

The results are plotted in figures 1 to 8 .

\subsection{Stochastic Simulation}

We next perform a stochastic simulation exercise. Let us suppose that $t_{0}=2$ and use the following steps:

( i ) Assume that at $t=1$ the economy is in its steady-state with $\hat{A}_{1}=0$;

( ii ) Use the "standard normal distribution random number generator" in Gauss to obtain a random shock $\varepsilon_{2}$;

\footnotetext{
${ }^{17}$ Note that $\hat{A}_{t}$ denotes the percentage deviation of $A_{t}$ from its steady-state value $A$.
} 
( iii ) From equation 82 above it follows that $\hat{A}_{2}=\varepsilon_{2}$. And using the same equation we can also compute the expected values of $\hat{A}_{s}$ for $s=3,4,5, \ldots$;

(iv ) Use the values from ( iii ) and the Blanchard and Khan algorithm to obtain the values of the "percentage deviation of each variable from its steady state" in period $t=2$;

( v ) Use the "standard normal distribution random number generator" in Gauss to obtain a random shock $\varepsilon_{3}$;

( vi ) From equation 82 above it follows that $\hat{A}_{3}=0.9 \hat{A}_{2}+\varepsilon_{3}$. And using the same equation we can also compute the expected values of $\hat{A}_{s}$ for $s=4,5,6, \ldots$;

( vii ) Use the values from ( vi ) and the Blanchard and Khan algorithm to obtain the values of the "percentage deviation of each variable from its steady state" in period $t=3$;

( viii ) $\ldots$

We can do this for 10000 periods and then summarize the statistical properties of the series we obtained for the various variables $\hat{y}_{t}, \hat{c}_{t}, \hat{\imath}_{t}, \hat{n}_{t}^{s}, \hat{w}_{t}, \ldots$

The results are shown in table 1 . 
Table 1. Stochastic simulation. Shocks in the firms' technological parameter.

\section{A. Standard deviations (s.d.)}

\begin{tabular}{|l|l|l|}
\hline Variable & s.d. & s.d. of the variable divided by the s.d. of $\hat{y}_{t}$ \\
\hline$\hat{y}_{t}$ & 4.20 & 1.00 \\
\hline$\hat{c}_{t}$ & 1.76 & 0.42 \\
\hline$\hat{\imath}_{t}$ & 21.49 & 5.12 \\
\hline$\hat{n}_{t}^{s}$ & 2.82 & 0.67 \\
\hline$\hat{w}_{t}$ & 2.00 & 0.48 \\
\hline$r_{t}^{e}-r$ & 0.04 & 0.01 \\
\hline
\end{tabular}

\section{B. Autocorrelations}

\begin{tabular}{|l|l|l|l|}
\hline Variable & correlation with $\hat{y}_{t-1}$ & correlation with $\hat{y}_{t-2}$ & correlation with $\hat{y}_{t-3}$ \\
\hline$\hat{y}_{t}$ & 0.906 & 0.824 & 0.751 \\
\hline Variable & correlation with $\hat{c}_{t-1}$ & correlation with $\hat{c}_{t-2}$ & correlation with $\hat{c}_{t-3}$ \\
\hline$\hat{c}_{t}$ & 0.997 & 0.993 & 0.989 \\
\hline
\end{tabular}

\begin{tabular}{|l|l|l|l|}
\hline Variable & correlation with $\hat{\imath}_{t-1}$ & correlation with $\hat{\imath}_{t-2}$ & correlation with $\hat{\imath}_{t-3}$ \\
\hline$\hat{\imath}_{t}$ & 0.885 & 0.783 & 0.695 \\
\hline
\end{tabular}

\begin{tabular}{|l|l|l|l|}
\hline Variable & correlation with $\hat{n}_{t-1}^{s}$ & correlation with $\hat{n}_{t-2}^{s}$ & correlation with $\hat{n}_{t-3}^{s}$ \\
\hline$\hat{n}_{t}^{s}$ & 0.883 & 0.781 & 0.691 \\
\hline
\end{tabular}

\begin{tabular}{|l|l|l|l|}
\hline Variable & correlation with $\hat{w}_{t-1}$ & correlation with $\hat{w}_{t-2}$ & correlation with $\hat{w}_{t-3}$ \\
\hline$\hat{w}_{t}$ & 0.974 & 0.950 & 0.928 \\
\hline
\end{tabular}

\begin{tabular}{|l|l|l|l|}
\hline Variable & correl. with $\left(r_{t-1}-r\right)$ & correl. with $\left(r_{t-2}-r\right)$ & correl. with $\left(r_{t-3}-r\right)$ \\
\hline$r_{t}^{e}-r$ & 0.889 & 0.792 & 0.707 \\
\hline
\end{tabular}

\section{Cross-correlations}




\begin{tabular}{|l|l|l|l|l|l|l|l|l|l|l|l|}
\hline Variable & \multicolumn{10}{|c|}{ Correlation with } \\
\hline & $\hat{y}_{t-12}$ & $\hat{y}_{t-8}$ & $\hat{y}_{t-4}$ & $\hat{y}_{t-2}$ & $\hat{y}_{t-1}$ & $\hat{y}_{t}$ & $\hat{y}_{t+1}$ & $\hat{y}_{t+2}$ & $\hat{y}_{t+4}$ & $\hat{y}_{t+8}$ & $\hat{y}_{t+12}$ \\
\hline$\hat{y}_{t}$ & 0.35 & 0.49 & 0.69 & 0.82 & 0.91 & 1.00 & 0.91 & 0.82 & 0.69 & 0.49 & 0.35 \\
\hline$\hat{c}_{t}$ & 0.64 & 0.64 & 0.61 & 0.59 & 0.58 & 0.56 & 0.51 & 0.47 & 0.41 & 0.30 & 0.23 \\
\hline$\hat{\imath}_{t}$ & 0.15 & 0.31 & 0.55 & 0.72 & 0.82 & 0.94 & 0.85 & 0.77 & 0.64 & 0.45 & 0.32 \\
\hline$\hat{n}_{t}^{s}$ & 0.10 & 0.27 & 0.51 & 0.69 & 0.79 & 0.91 & 0.82 & 0.74 & 0.61 & 0.43 & 0.30 \\
\hline$\hat{w}_{t}$ & 0.60 & 0.65 & 0.72 & 0.76 & 0.79 & 0.81 & 0.74 & 0.68 & 0.57 & 0.42 & 0.31 \\
\hline$r_{t}^{e}-r$ & -0.07 & 0.10 & 0.35 & 0.53 & 0.64 & 0.77 & 0.69 & 0.62 & 0.51 & 0.35 & 0.24 \\
\hline
\end{tabular}

In these tables, $\left(r_{t}^{e}-r\right)$ denotes the deviation of the ex-ante real interest rate from its steadystate value.

We may summarize as follows the main results obtained in table 1 and in figures 1 to 8 . First: consumption, investment and "labour effort" are procyclical. Second: consumption is less volatile than output and investment is more volatile than output. These are very well documented stylized facts about the United States economy [ references on this include Kydland and Prescott (1990) and Backus and Kehoe (1992)].

Our pattern of results is similar to the one obtained by King, Plosser and Rebelo (1988). The reason why our results are not exactly the same as those obtained by King, Plosser and Rebelo has to do both with the fact that ours is a zero growth version of their model and with the fact that our calibration is slightly different. For example, in our calibration the investment share of output was set at 0.167 whereas King, Plosser and Rebelo use the value 0.295 (their value probably results from including expenditure on consumer durables in the total amount of investment expenditure).

\section{Conclusion}

We have presented a detailed derivation of the competitive equilibrium of an economy. We have used a decentralized way of obtaining this equilibrium and have specified all the assumptions involved. Our method makes clear how each of these assumptions could be replaced by a different one and still let us proceed with the derivation of the general equilibrium without much difficulty. 
Although we have arrived at the same set of equations as King, Plosser and Rebelo (1988) - who use a central planner's approach - our method has the advantage that it can be used in many situations where the second welfare theorem does not hold.

It results obvious that we are able to generate the same key business cycle facts that King, Plosser and Rebelo are able to generate with their model: (i) consumption, investment and work hours are procyclical; (ii) consumption is less volatile than real output whereas investment is more volatile than real output. 


\section{Appendix}

In this appendix, we derive in an intuitive way the first order conditions of the firms' problem and the first order conditions of the households' problem. Let us start with the firms' problem.

The first order condition in terms of the choice of labour demand can be obtained as follows.

The expected marginal benefit of increasing $n_{t_{0}+j}^{d}$ by one unit is the increased output that will be obtained. This is given by the marginal product of labour, $A_{t_{o}+j} F_{2}\left(k_{t_{0}+j}, n_{t_{0}+j}^{d}\right)$. Discounting this to period $t_{0}$, we have

$$
\frac{A_{t_{o}+j} F_{2}\left(k_{t_{0}+j,} n_{t_{0}+j}^{d}\right)}{\left(1+r_{t_{0}}\right) \ldots\left(1+r_{t_{0}-1+j}\right)}
$$

Since the firm is in period $t_{0}$ when it is making these decisions, it must think in terms of

$$
E_{t_{0}}\left[\frac{A_{t_{o}+j} F_{2}\left(k_{t_{0}+j}, n_{t_{0}+j}^{d}\right)}{\left(1+r_{t_{0}}\right) \ldots\left(1+r_{t_{0}-1+j}\right)}\right]
$$

The expected marginal cost of increasing $n_{t_{0}+j}^{d}$ by one unit is the wage payment that it implies, $w_{t_{0}+j}$. Discounting this amount to period $t_{0}$, we have

$$
\frac{w_{t_{0}+j}}{\left(1+r_{t_{0}}\right) \ldots\left(1+r_{t_{0}-1+j}\right)}
$$

Since the firm is in period $t_{0}$ when it is making these decisions, it must think in terms of

$$
E_{t_{0}}\left[\frac{w_{t_{0}+j}}{\left(1+r_{t_{0}}\right) \ldots\left(1+r_{t_{0}-1+j}\right)}\right]
$$

The optimal choice of $n_{t_{0}+j}^{d}$ is the point where expected marginal benefit is equal to expected marginal cost. Therefore, the condition is

$$
E_{t_{0}}\left[\frac{A_{t_{o}+j} F_{2}\left(k_{t_{0}+j}, n_{t_{0}+j}^{d}\right)}{\left(1+r_{t_{0}}\right) \ldots\left(1+r_{t_{0}-1+j}\right)}\right]=E_{t_{0}}\left[\frac{w_{t_{0}+j}}{\left(1+r_{t_{0}}\right) \ldots\left(1+r_{t_{0}-1+j}\right)}\right]
$$

Let us now try to obtain the first order condition in terms of the choice of capital. Note that in period $\left(t_{0}+j\right)$ the household chooses $k_{t_{0}+1+j} . k_{t_{0}+j}$ is pre-determined [it was determined in period $\left.\left(t_{0}-1+j\right)\right]$. 
The expected marginal benefit of increasing $k_{t_{0}+1+j}$ by one unit is obtained as follows. If, in period $\left(t_{0}+j\right)$, the firm decides to increase $k_{t_{0}+1+j}$ by one unit, that extra unit of capital shall produce an increase in output in period $\left(t_{0}+1+j\right)$ given by $A_{t_{o}+1+j} F_{1}\left(k_{t_{0}+1+j}, n_{t_{0}+1+j}^{d}\right)$. The use of capital in production involves depreciation so that, after production, all that is left of that extra unit of capital is $(1-\delta)$ units of capital [or $(1-\delta)$ units of output since units of capital in this model correspond to units of output]. Therefore, the overall benefit of increasing $k_{t_{0}+1+j}$ in period $\left(t_{0}+j\right)$ by one unit is that in period $\left(t_{0}+1+j\right)$ the firm will obtain $\left[A_{t_{o}+1+j} F_{1}\left(k_{t_{0}+1+j}, n_{t_{0}+1+j}^{d}\right)+(1-\delta)\right]$ units of output. Discounting this amount to period $t_{0}$, we obtain

$$
\frac{A_{t_{o}+1+j} F_{1}\left(k_{t_{0}+1+j}, n_{t_{0}+1+j}^{d}\right)+(1-\delta)}{\left(1+r_{t_{0}}\right) \ldots\left(1+r_{t_{0}-1+j}\right)\left(1+r_{t_{0}+j}\right)}
$$

Since the firm is in period $t_{0}$ when it is making these decisions, it must think in terms of

$$
E_{t_{0}}\left[\frac{A_{t_{o}+1+j} F_{1}\left(k_{t_{0}+1+j}, n_{t_{0}+1+j}^{d}\right)+(1-\delta)}{\left(1+r_{t_{0}}\right) \ldots\left(1+r_{t_{0}-1+j}\right)\left(1+r_{t_{0}+j}\right)}\right]
$$

The expected marginal cost of increasing $k_{t_{0}+1+j}$ by one unit is the reduction in the amount of dividends paid in period $\left(t_{0}+j\right)$. This reduction in real terms corresponds to one unit of output: the one unit of output that is used for investment. Discounting this amount to period $t_{0}$, we have

$$
\frac{1}{\left(1+r_{t_{0}}\right) \ldots\left(1+r_{t_{0}-1+j}\right)}
$$

Since the firm is in period $t_{0}$ when it is making these decisions, it must think in terms of

$$
E_{t_{0}}\left[\frac{1}{\left(1+r_{t_{0}}\right) \ldots\left(1+r_{t_{0}-1+j}\right)}\right]
$$

Hence, the first order condition in terms of the choice of capital is

$$
\begin{gathered}
E_{t_{0}}\left[\frac{A_{t_{o}+1+j} F_{1}\left(k_{t_{0}+1+j}, n_{t_{0}+1+j}^{d}\right)+(1-\delta)}{\left(1+r_{t_{0}}\right) \ldots\left(1+r_{t_{0}-1+j}\right)\left(1+r_{t_{0}+j}\right)}\right]= \\
=E_{t_{0}}\left[\frac{1}{\left(1+r_{t_{0}}\right) \ldots\left(1+r_{t_{0}-1+j}\right)}\right]
\end{gathered}
$$

Let us now derive the first order conditions for the household's problem in an intuitive way. 
We start by defining $\lambda_{t_{0}+j}$ as the marginal utility of output in period $\left(t_{0}+j\right)$. In other words, $\lambda_{t_{0}+j}$ gives us the increase/decrease in an household's utility that would follow an increase/decrease of one (infinitesimal) unit in the amount of output available to that household. This corresponds to the increase/decrease in the household's utility that would be caused by consuming one more/less unit of output.

In short, $\lambda_{t_{0}+j}$ is defined as giving us the marginal utility that the consumer would obtain if he/she were given an extra unit of output to consume. Mathematically, then, we can write

$$
\lambda_{t_{0}+j}=u_{1}\left(c_{t_{0}+j}, 1-n_{t_{0}+j}^{s}\right)
$$

Applying the expectations operator to both sides of this equation we obtain

$$
E_{t_{0}}\left[\lambda_{t_{0}+j}\right]=E_{t_{0}}\left[u_{1}\left(c_{t_{0}+j}, 1-n_{t_{0}+j}^{s}\right)\right]
$$

Let us now look at the optimal choice of $n_{t_{0}+j}^{s}$.

The expected marginal cost of increasing $n_{t_{0}+j}^{s}$ by one unit is that this implies a reduction of one unit in the amount of leisure that the household enjoys during period $\left(t_{0}+j\right)$. The decrease in utility that results from this is given by $u_{2}\left(c_{t_{0}+j}, \ell_{t_{0}+j}\right)=u_{2}\left(c_{t_{0}+j}, 1-n_{t_{0}+j}^{s}\right)$. Since we are taking decisions at period $t_{0}$, we have to use the expected value of this amount which is $E_{t_{0}}\left[u_{2}\left(c_{t_{0}+j}, 1-n_{t_{0}+j}^{s}\right)\right]$.

The expected marginal benefit of increasing $n_{t_{0}+j}^{s}$ by one unit is that we receive $w_{t_{0}+j}$ units of output. In period $\left(t_{0}+j\right)$ utility terms, the value of this is $\lambda_{t_{0}+j} w_{t_{0}+j}$. Since the household is taking decisions at period $t_{0}$, it has to think in terms of $E_{t_{0}}\left[\lambda_{t_{0}+j} w_{t_{0}+j}\right]$.

The first order condition on $n_{t_{0}+j}^{s}$ is obtained by equating expected marginal cost to expected marginal benefit. Hence, the condition is

$$
E_{t_{0}}\left[u_{2}\left(c_{t_{0}+j}, 1-n_{t_{0}+j}^{s}\right)\right]=E_{t_{0}}\left[\lambda_{t_{0}+j} w_{t_{0}+j}\right]
$$

Let us now look at the optimal choice of $b_{t_{0}+1+j}$. Note that in period $\left(t_{0}+j\right)$ the household chooses $b_{t_{0}+1+j} . b_{t_{0}+j}$ is pre-determined [it was determined in period $\left(t_{0}-1+j\right)$ ].

The expected marginal cost of increasing $b_{t_{0}+1+j}$ [the amount of output paid to other households in period $\left(t_{0}+1+j\right)$ ] by one unit is the corresponding loss in utility. By having one less unit 
of output in period $\left(t_{0}+1+j\right)$, the household loses $\lambda_{t_{0}+1+j}$ in period $\left(t_{0}+1+j\right)$ utility terms. Discounting this to period $\left(t_{0}+j\right)$ utility we obtain $\beta \lambda_{t_{0}+1+j}$. Since plans are being made in period $t_{0}$, the household has to think in terms of $E_{t_{0}}\left[\beta \lambda_{t_{0}+1+j}\right]$.

The expected marginal benefit of increasing $b_{t_{0}+1+j}$ [the amount paid to other households in period $\left(t_{0}+1+j\right)$ ] by one unit is obtained as follows. If the household is going to pay one more unit of output in period $\left(t_{0}+1+j\right)$ it must be because it borrowed an extra $\frac{1}{\left(1+r_{t_{0}+j}\right)}$ units of output in period $\left(t_{0}+j\right)$. In period $\left(t_{0}+j\right)$ utility terms, this is worth $\frac{\lambda_{t_{0}+j}}{\left(1+r_{t_{0}+j}\right)}$. Since plans are being made in period $t_{0}$, the household has to think in terms of $E_{t_{0}}\left[\frac{\lambda_{t_{0}+j}}{\left(1+r_{t_{0}+j}\right)}\right]$.

The first order condition on $b_{t_{0}+1+j}$ is obtained by equating expected marginal cost to expected marginal benefit. Hence, the condition is

$$
E_{t_{0}}\left[\frac{\lambda_{t_{0}+j}}{\left(1+r_{t_{0}+j}\right)}\right]=E_{t_{0}}\left[\beta \lambda_{t_{0}+1+j}\right]
$$

Let us now look at the optimal choice of $z_{t_{0}+1+j}^{f}$.

The expected marginal cost of increasing $z_{t_{0}+1+j}^{f}$ by one unit is obtained as follows. If the household decides to buy a fraction $(1 / v)$ of firm $\mathrm{f}$ in period $\left(t_{0}+j\right)$, it will have to pay $(1 / v) q_{t_{0}+j}^{f}$. In period $\left(t_{0}+j\right)$ utility terms, the value of this is $\lambda_{t_{0}+j}(1 / v) q_{t_{0}+j}^{f}$. Since the household is at $t_{0}$ when it is making these plans, it must think in terms of $E_{t_{0}}\left[\lambda_{t_{0}+j}(1 / v) q_{t_{0}+j}^{f}\right]$.

The expected marginal benefit of increasing $z_{t_{0}+1+j}^{f}$ by one unit is obtained as follows. If the household buys a fraction $(1 / v)$ of firm $\mathrm{p}$ in period $\left(t_{0}+j\right)$, it will be entitled to a share in the dividends in period $\left(t_{0}+1+j\right)$ amounting to $(1 / v) \pi_{t_{0}+1+j}^{f}$. In addition to this, the household will be able to sell this fraction $(1 / v)$ of firm $\mathrm{p}$ in period $\left(t_{0}+1+j\right)$ thereby earning $(1 / v) q_{t_{0}+1+j}^{f}$. In period $\left(t_{0}+1+j\right)$ utility terms the sum of the two amounts that the household receives is worth $\lambda_{t_{0}+1+j}\left[(1 / v) \pi_{t_{0}+1+j}^{f}+(1 / v) q_{t_{0}+1+j}^{f}\right]$. In period $\left(t_{0}+j\right)$ utility terms, the value of this is $\beta \lambda_{t_{0}+1+j}\left[(1 / v) \pi_{t_{0}+1+j}^{f}+(1 / v) q_{t_{0}+1+j}^{f}\right]$. Since the household is at $t_{0}$ when it is making these plans, it must think in terms of $E_{t_{0}}\left[\beta \lambda_{t_{0}+1+j}\left[(1 / v) \pi_{t_{0}+1+j}^{f}+(1 / v) q_{t_{0}+1+j}^{f}\right]\right]$.

Therefore, the condition is

$$
E_{t_{0}}\left[\lambda_{t_{0}+j}(1 / v) q_{t_{0}+j}^{f}\right]=E_{t_{0}}\left[\beta \lambda_{t_{0}+1+j}\left[(1 / v) \pi_{t_{0}+1+j}^{f}+(1 / v) q_{t_{0}+1+j}^{f}\right]\right]
$$

or equivalently 


$$
E_{t_{0}}\left[\lambda_{t_{0}+j} q_{t_{0}+j}^{f}\right]=E_{t_{0}}\left[\beta \lambda_{t_{0}+1+j}\left(\pi_{t_{0}+1+j}^{f}+q_{t_{0}+1+j}^{f}\right)\right]
$$

When making its plans regarding present and future amounts of consumption, work effort, borrowing and shares, the household must also take into account the budget constraints that it will be facing in each period (present and future). The budget constraint for period $\left(t_{0}+j\right)$ is given by

$$
w_{t_{0}+j} n_{t_{0}+j}^{s}+\frac{b_{t_{0}+1+j}}{1+r_{t_{0}+j}}+\sum_{f=1}^{f=F} z_{t_{0}+j}^{f} \pi_{t_{0}+j}^{f}=c_{t_{0}+j}+b_{t_{0}+j}+\sum_{f=1}^{f=F} q_{t_{0}+j}^{f}\left(z_{t_{0}+1+j}^{f}-z_{t_{0}+j}^{f}\right)
$$

Since the household is at $t_{0}$ when it is making its plans, it must think in terms of

$$
\begin{aligned}
& E_{t_{0}}\left[w_{t_{0}+j} n_{t_{0}+j}^{s}+\frac{b_{t_{0}+1+j}}{1+r_{t_{0}+j}}+\sum_{f=1}^{f=F} z_{t_{0}+j}^{f} \pi_{t_{0}+j}^{f}\right]= \\
& =E_{t_{0}}\left[c_{t_{0}+j}+b_{t_{0}+j}+\sum_{f=1}^{f=F} q_{t_{0}+j}^{f}\left(z_{t_{0}+1+j}^{f}-z_{t_{0}+j}^{f}\right)\right]
\end{aligned}
$$




\section{References}

[1] Backus, D. and Kehoe, P. 1992. International evidence on the historical properties of business cycles. American Economic Review 82: 864-888.

[2] Blanchard, O. and Khan, C. (1980). The solution of linear difference models under rational expectations. Econometrica 48: 1305-1311.

[3] Hansen, G. 1985. Indivisible labor and the business cycle. Journal of Monetary Economics 56: $309-327$.

[4] King, R., Plosser, C. and Rebelo, S. (1988). Production, growth and business cycles: I. The basic neoclassical model. Journal of Monetary Economics 21: 195-232.

[5] Kydland, F. and Prescott, E. (1982). Time to build and aggregate fluctuations. Econometrica 50: $1345-1370$.

[6] Kydland, F. and Prescott, E. 1990. Business cycles: real facts and a monetary myth. Quarterly Review. Federal Reserve Bank of Minneapolis, Spring.

[7] Long, J. and Plosser, C. (1983). Real Business Cycles. Journal of Political Economy 91: 39-69. 

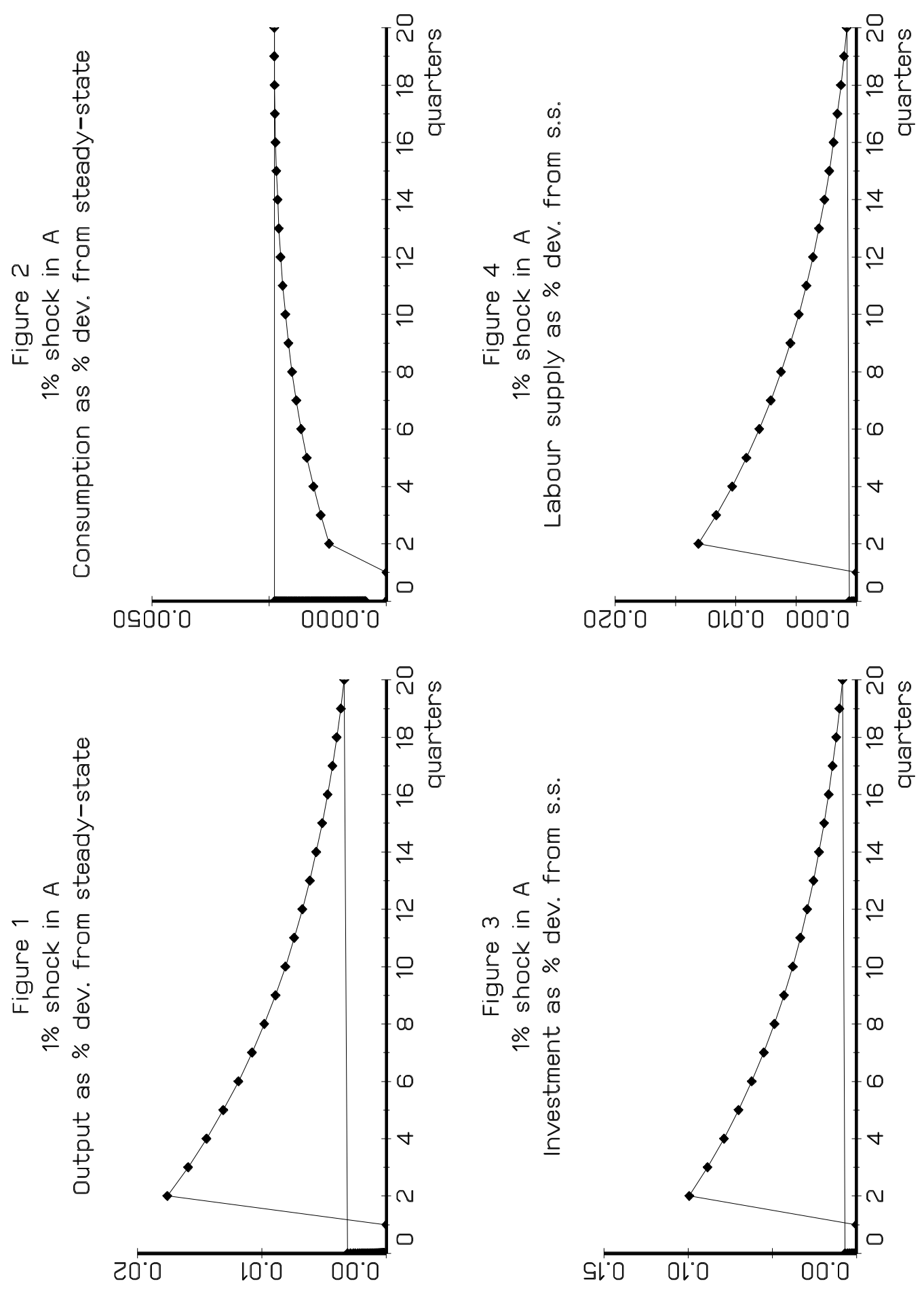

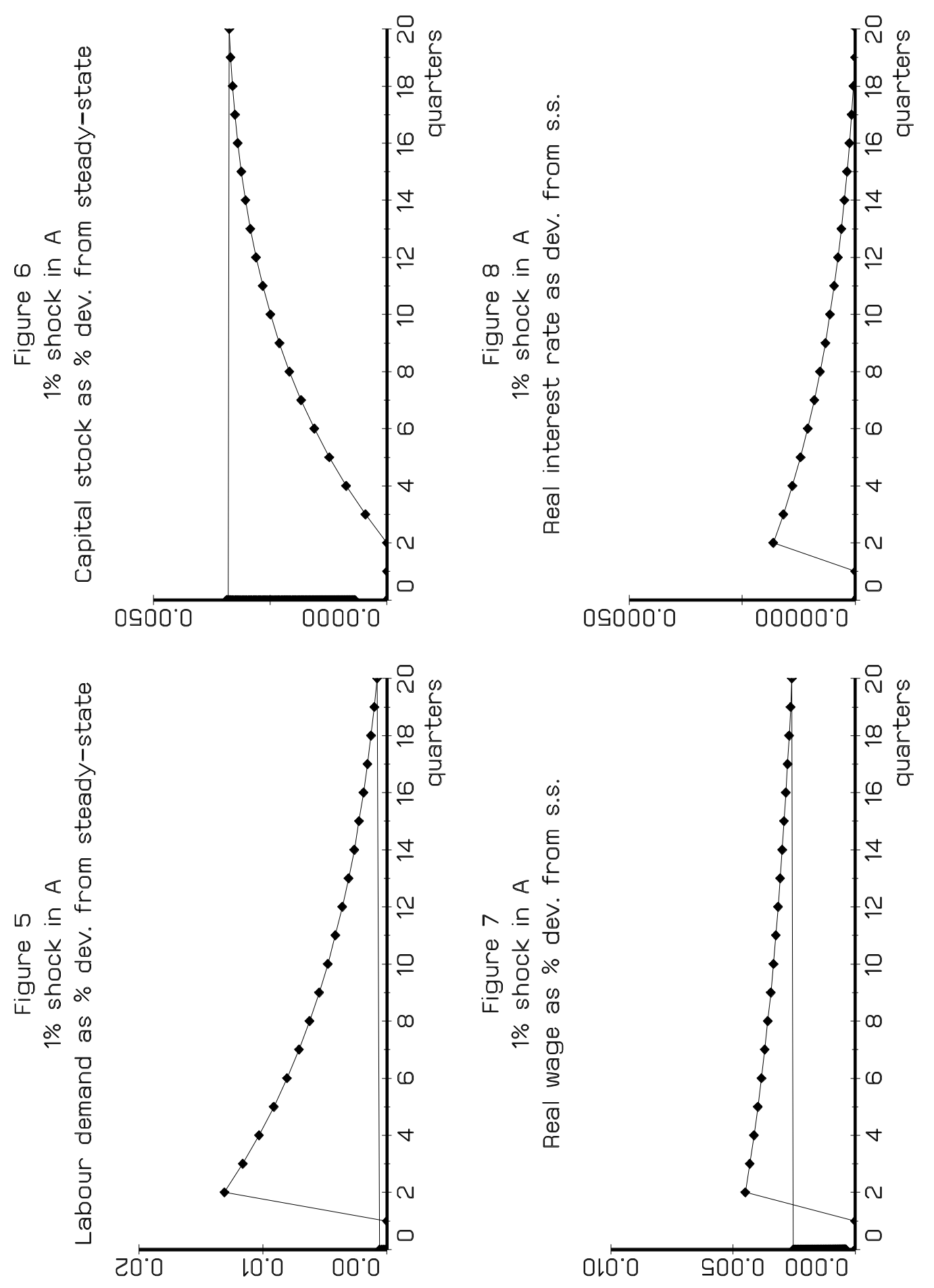